\title{
Caracterização da plataforma e do talude continentais do Estado da Bahia, a partir da análise de agrupamento dos dados sedimentológicos e da microfauna de foraminíferos
}

\author{
Ângela Cristina da Fonseca MIRANTE ${ }^{1}$, João Domingos SCALON², Tânia Maria Fonseca ARAÚJO³ \& Heli- \\ sângela Acris Borges de ARAÚJO ${ }^{3}$
}

1. Instituto Federal de Educação, Ciência e Tecnologia da Bahia, Departamento de Ciências Aplicadas. Rua Emídio dos Santos, s/no - Barbalho, CEP 40300-010, Salvador, BA, Brasil. E-mail: angelamirante@ifba.edu.br.

2. Universidade Federal de Lavras, Departamento de Exatas. Caixa Postal 3037, CEP 37200-000, Lavras, MG, Brasil. E-mail: scalon@dex. ufla.br.

3. Universidade Federal da Bahia, Grupo de Estudos de Foraminíferos, Instituto de Geociências. Rua Caetano Moura, 123, Federação, CEP 40210-340, Salvador, BA, Brasil. E-mail: tfaraujo@ufba.br, hacris@gmail.com.

Recebido em 02/2012. Aceito para publicação em 06/2013.

Versão online publicada em xx/xx/20xx (www.pesquisasemgeociencias.ufrgs.br)

\begin{abstract}
Resumo - Esse trabalho teve como objetivo caracterizar a plataforma e o talude continentais do Estado da Bahia, a partir da análise multivariada aplicada aos dados de sedimento e da microfauna de foraminíferos. Trinta e oito amostras de sedimento da superfície do fundo foram analisadas e processadas de acordo com a metodologia padrão para estudos sedimentológicos (granulometria e composição) e microfaunísticos. Na fração destinada à análise da microfauna de foraminíferos foram triadas e identificadas as primeiras trezentas testas. Para a realização da análise multivariada foram utilizadas as espécies que possuíam, ao mesmo tempo, frequência de ocorrência maior que 50 \% (constantes) e frequência relativa maior que $5 \%$ (principais) em pelo menos duas amostras. A metodologia consistiu na aplicação da técnica de agrupamento em que foi definida a distância euclidiana ao quadrado como métrica de formação dos grupos, utilizando os métodos Ward e k-Médias. Uma análise de agrupamento das espécies (modo R) foi realizada, a partir dos dados de frequência absoluta, para os diferentes intervalos batimétricos. Em seguida, foi aplicada uma análise de agrupamento entre as amostras (modo Q), a partir dos teores de sedimento presentes em cada amostra. A integração dos dados, a partir dos dendrogramas gerados pela análise multivariada, revelou que nas plataformas interna e média predominou areia siliciclástica; na plataforma externa areia carbonática cascalhosa e no talude areia carbonática lamosa. As espécies Archaias angulatus e Peneroplis proteus, apresentaram distribuição estreitamente relacionada com areia siliciclástica, a distribuição de Discorbis mira esteve associada com areia carbonática e Cassidulina laevigata e Cibicides pseudoungerianus foram associadas com areia carbonática lamosa. Amphistegina lessonii, Amphistegina gibbosa e, principalmente, Peneroplis carinatus apresentaram distribuição relacionada com sedimentação em área de transição entre areia siliciclástica e areia carbonática. Globigerinoide ruber, planctônica, foi encontrada principalmente em sedimento do tipo areia carbonática lamosa, localizado mais distante da costa.
\end{abstract}

Palavras-chaves: Análise multivariada, método Ward, método k-Médias, foraminíferos.

Abstract - CHARACTERIZATION OF THE CONTINENTAL SHELF AND SLOPE OF THE STATE OF BAHIA, FROM THE CLUSTER ANALYSIS OF SEDIMENTOLOGICAL DATA AND THE FORAMINIFERA MICROFAUNA. This study aimed to characterize the continental shelf and slope of the State of Bahia, based on the multivariate analysis applied to sediments data and the foraminifers' microfauna. Thirty-eight samples from the bottom sediment surface were analyzed, which were processed in accordance with the standard methodology for sediment studies (grain size and composition) and microfaunal analysis. From the sediment fraction used for the foraminifers' micro fauna analysis, the first 300 tests were randomly sorted and identified. For the multivariate analysis, it was used species that have at the same time frequency of occurrence higher than $50 \%$ (constant) and relative frequency greater than 5\% (major) in, at least, two samples. The methodology consisted in the application of the technique of multivariate grouping in which it was set the squared Euclidean distance defined as a metric formation of groups, applying the methods Ward's and k-Means. A cluster analysis of species (R mode) was performed based on the absolute frequency data for each different bathymetric range. Then, a cluster analysis was applied between the samples ( $Q$ mode) based on the percent of sediment present in each sample. The dendograms data integration, generated by the multivariate analysis, revealed that siliciclastic sands predominate in the inner and middle continental shelves, carbonate gravelly sands dominated in the outer shelf and carbonate muddy sands were the major sediment type found in the continental slope. The distribution of Archaias angulatus and Peneroplis proteus was closely related to the occurrence of siliciclastic sands, while the Discorbis mira was associated with carbonate sands, and Cassidulina laevigata and Cibicides pseudoungerianus were associated to carbonate muddy sands. The distribution of Amphistegina lessonii, Amphistegina gibbosa and especially 
Peneroplis carinatus was associated with the sediments from the transition between siliciclastic and carbonate sands. The planktonic Globigerinoide ruber was particularly found in carbonate muddy sands located farther from the coast.

Keywords: Multivariate analysis, Ward's method, k-Means's method, foraminifera.

\section{Introdução}

Nas margens continentais ocorre a transição fisiográfica entre os continentes (crosta continental) e as bacias oceânicas (crosta oceânica). Apesar de representarem apenas $20 \%$ da superfície coberta pelos oceanos, as margens continentais concentram $90 \%$ do potencial econômico do ecossistema marinho, representado por recursos bióticos, minerais e energéticos (Asmus, 1984). Nesta área, o Brasil prospecta mais de $80 \%$ de seu petróleo e mais de $50 \%$ de seu gás natural.

Em linhas gerais, a localização geográfica favorável à captação e distribuição de recursos terrestres e marinhos e a diversidade de ecossistemas associados, destacando-se principalmente praias, recifes, plataforma e talude continentais, ajudam a explicar a acentuada exploração de recursos da margem continental. Também alterações físicas diretas, resultantes de atividades como a construção de barragens ao longo de bacias hidrográficas, dragagem de portos, aterros, despejo de resíduos sólidos, derrubada de florestas litorâneas, além de atividades de turismo e recreação contribuem para o impacto ambiental nesta área (PNUMA, 2004).

Neste contexto, o uso de organismos como indicadores ecológicos tem sido amplamente empregado. Entre os organismos da microfauna marinha utilizada em estudos oceanográficos, os foraminíferos ocupam uma posição bastante significativa na biota oceânica e são reconhecidamente excelentes indicadores ecológicos e paleoecológicos. As testas desses organismos revelam algumas propriedades físico-químicas dos oceanos tornando-os potenciais indicadores de mudanças climáticas, de ocorrência de agentes poluidores e da dinâmica dos oceanos (Bergue \& Coimbra, 2008).

Devido ao tamanho microscópico dos foraminíferos, em pequenas amostras de sedimento é encontrada uma grande quantidade de indivíduos e de espécies, o que permite trabalhar com dados estatísticos expressivos (Araújo \& Araújo, 2010). Associado a isso, estudos revelaram que existe uma grande microfauna de foraminíferos presente nos sedimentos de superfície e subsuperfícies da plataforma e do talude continentais (Passos et al., 2001; Araújo \& Machado, 2008a, 2008b).

Nas últimas décadas, devido ao avanço tecnológico, intensificou-se a obtenção de dados geológicos e biológicos quantitativos. Entretanto, a maioria das informações coletadas não é analisada estatisticamente (Landim, 2011). Em estudos para descrição biológica das associações de foraminíferos, geralmente, é utilizada uma metodologia clássica de análises estatísticas descritivas e medidas tais como: número de indivíduos, frequência relativa, número de espécie ou riqueza e o índice de diversidade de Shannon-Wiener (Vieira, 2011). Observa-se também, o uso de técnicas estatísticas multivariadas, como análises de agrupamentos (Clarke \& Warwick, 2001; Pawlowski \& Holzmann, 2008; Araújo, 2009).

Em estudos oceanográficos, as assembleias de foraminíferos obtidas de diferentes localidades requerem análise e interpretação de dados provenientes de um grande número de variáveis. Nesse caso, a análise estatística multivariada se faz necessária, pois os procedimentos desenvolvidos por estas técnicas analisam os dados através da combinação das inúmeras variáveis, facilitando a compreensão da variabilidade total dos dados. Com a aplicação da análise estatística multivariada será possível relacionar as variáveis envolvidas no processo e, mais precisamente, avaliar a relação tanto entre as espécies da microfauna de foraminíferos, como entre as espécies e os parâmetros abióticos, a exemplo da profundidade e do sedimento. Portanto, se o interesse na utilização destas técnicas é verificar como as amostras se relacionam, ou seja, o quanto estas são semelhantes segundo as variáveis analisadas no trabalho, o método a ser aplicado será a análise por agrupamento.

A análise de agrupamento aplicada à exploração dos dados é uma ferramenta estatística que visa agrupar objetos semelhantes segundo suas características (variáveis) ou agrupar variáveis segundo os valores obtidos pelos objetos (Bussab et al., 1990). A idéia é maximizar a homogeneidade de objetos dentro de grupos, ao mesmo tempo em que se maximiza a heterogeneidade entre os grupos (Hair et al., 2005).

Esse trabalho tem como objetivo caracterizar a plataforma e talude continentais do estado da Bahia, a partir da análise multivariada aplicada aos dados dos sedimentos e da microfauna de foraminíferos. Essa análise permite avaliar as condições sedimentológica e hidrodinâmica atuais, além de servir de subsídio para futuros estudos de biomonitoramento da margem continental em estudo.

\section{2 Área, material e métodos}

\subsection{Localização da área}

Este trabalho apresenta como área de estudo o trecho da plataforma continental norte do estado da Bahia, situado entre a praia da Barra, no município de Salvador, e a foz do rio Itariri, no município de Mata de São João, entre as coordenadas longitudinais $37^{\circ} 30^{\prime} \mathrm{W}$ e $38^{\circ} 30^{\prime} \mathrm{W}$ e latitudinais $12^{\circ} \mathrm{S}$ e $13^{\circ} 8^{\prime} \mathrm{S}$. Essa área tem 
uma extensão costeira de aproximadamente $131 \mathrm{~km}$, abrangendo as plataformas interna, média e externa e o talude continental superior, com área de $2.227 \mathrm{~km}^{2}$. A figura 1 mostra a localização da área e das estações de coleta das amostras.

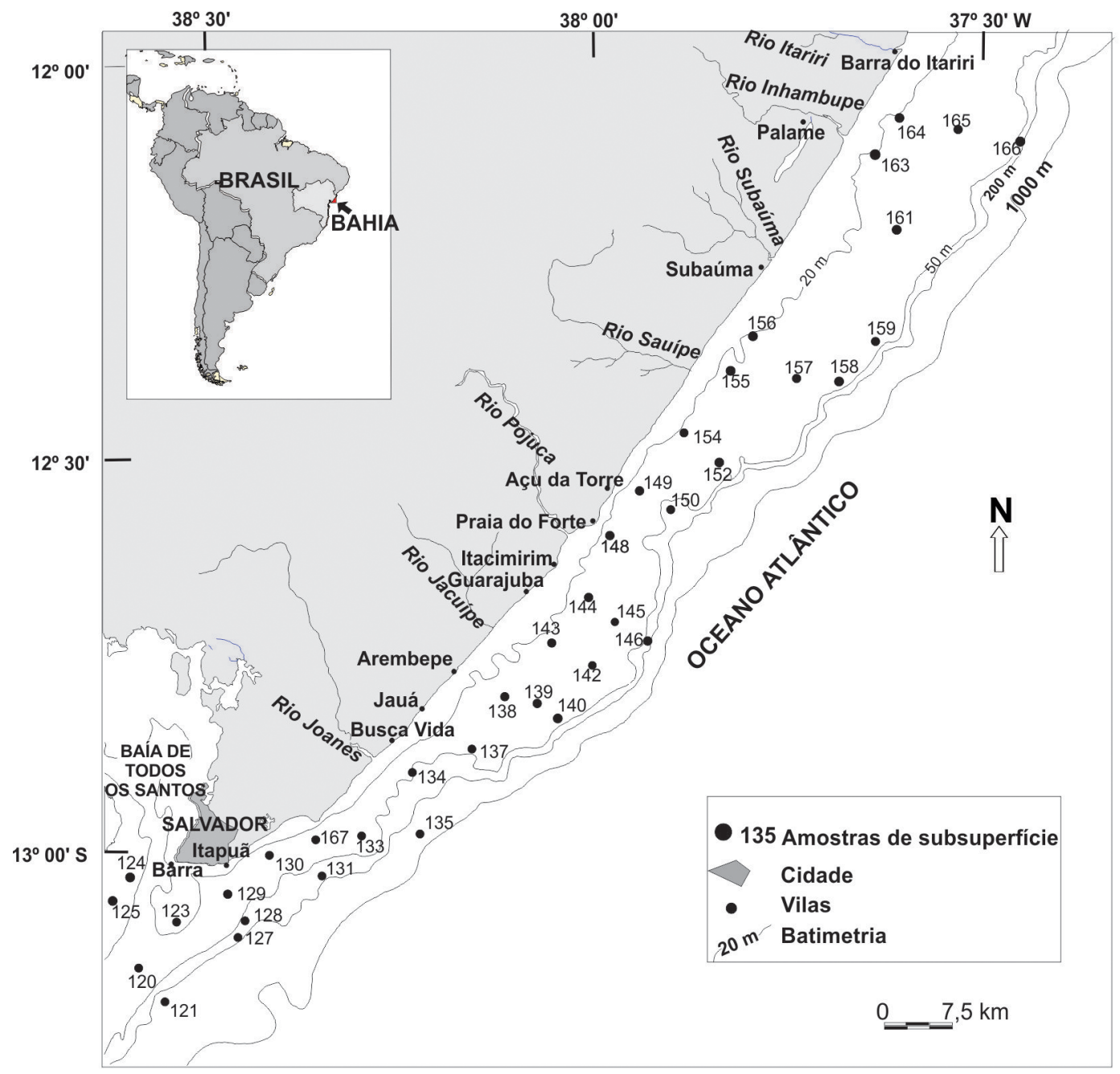

Figura 1. Localização da área de estudo e das estações de coleta das amostras (conforme Araújo, 2010).

\subsection{Localização e preparação das amostras}

As amostras foram coletadas durante a operação GEOMAR XXV, em 1985, e estão arquivadas no Instituto de Geociências da Universidade Federal da Bahia. A operação GEOMAR XXV foi executada a bordo do navio oceanográfico Almirante Câmara, da Marinha Brasileira, Diretoria de Hidrografia e Navegação (DHN), cobrindo a área da plataforma continental e talude superior dos estados de Alagoas, Sergipe e Bahia. Foi utilizada a draga tipo Gibbs para coletar as amostras de superfície.

Neste trabalho foram analisadas trinta e oito amostras do sedimento da superfície do fundo e as posições das estações de coleta estão apresentadas em coordenadas geográficas na tabela 1 e sua distribuição espacial encontra-se representada na figura 1. As amostras foram agrupadas de acordo com a profundidade em que foram aleatoriamente coletadas, com intuito de examinar a variação na distribuição da mi- crofauna de foraminíferos nas zonas batimétricas da plataforma e do talude continentais. Dessa forma, para expressar a fisiografia (estreita) e a batimetria (rasa) da área em estudo, as amostras foram agrupadas em subambientes delimitados da seguinte maneira: plataforma interna (de 0 a $20 \mathrm{~m}$ ), contendo cinco amostras; plataforma média( de $>20$ a $40 \mathrm{~m}$ ), contendo 16 amostras; plataforma externa (de $>40$ a $60 \mathrm{~m}$ ), contendo 11 amostras; e talude superior (de 80 a $300 \mathrm{~m}$ ), com seis amostras (Tab. 1).

Esses contornos batimétricos, com intervalos de $20 \mathrm{~m}$ sobre a plataforma e intervalos de $400 \mathrm{~m}$ sobre o talude, seguiram subdivisão adotada por França (1979) no Projeto Reconhecimento Global da Margem Continental Brasileira (REMAC).

A área com profundidade de 60 a 80 m corresponde à quebra da plataforma continental, não sendo possível a coleta de amostras por ser de difícil acesso. 
Tabela 1. Profundidade e coordenadas das amostras de subsuperfície estudadas. Conforme Araújo, 2010.

\begin{tabular}{|c|c|c|c|c|}
\hline $\begin{array}{c}\text { Amostras } \\
\text { (Superfície) }\end{array}$ & Profundidade (m) & Local & Latitude (S) & Longitude (W) \\
\hline 123 & 14 & Plataforma interna & $13^{\circ} 05^{\prime} 31^{\prime \prime}$ & $38^{\circ}$ o 32' 02" \\
\hline 124 & 15 & Plataforma interna & $13^{\circ} 01^{\prime} 36^{\prime \prime}$ & $38^{\circ} 34^{\prime} 53^{\prime \prime}$ \\
\hline 125 & 17,7 & Plataforma interna & $13^{\circ} 03^{\prime} 26^{\prime \prime}$ & $3823^{\prime} 50^{\prime \prime}$ \\
\hline 156 & 19 & Plataforma interna & $12^{\circ} 19^{\prime} 56^{\prime \prime}$ & $37^{\circ} 48^{\prime} 08^{\prime \prime}$ \\
\hline 164 & 20 & Plataforma interna & $12^{\circ} 03^{\prime} 24^{\prime \prime}$ & $37^{\circ} 36^{\prime} 57^{\prime \prime}$ \\
\hline 155 & 21,5 & Plataforma média & $12^{\circ} 22^{\prime} 46^{\prime \prime}$ & $3749^{\prime} 50^{\prime \prime}$ \\
\hline 143 & 22,1 & Plataforma média & $12^{\circ} 43^{\prime} 26^{\prime \prime}$ & $3803^{\prime} 37^{\prime \prime}$ \\
\hline 154 & 23 & Plataforma média & $12^{\circ} 27^{\prime} 32^{\prime \prime}$ & $37^{\circ} 53^{\prime} 15^{\prime \prime}$ \\
\hline 138 & 26 & Plataforma média & $12^{\circ} 47^{\prime} 39^{\prime \prime}$ & 38 o $07^{\prime} 03^{\prime \prime}$ \\
\hline 144 & 26,4 & Plataforma média & $12^{\circ} 40^{\prime} 13^{\prime \prime}$ & $38000^{\prime} 44^{\prime \prime}$ \\
\hline 133 & 27 & Plataforma média & $12^{\circ} 58^{\prime} 25^{\prime \prime}$ & $38^{\circ} 18^{\prime} 10^{\prime \prime}$ \\
\hline 161 & 28 & Plataforma média & $12^{\circ} 11^{\prime} 42^{\prime \prime}$ & $37^{\circ} 36^{\prime} 53^{\prime \prime}$ \\
\hline 163 & 28 & Plataforma média & $12^{\circ} 06^{\prime} 13^{\prime \prime}$ & $37^{\circ} 38^{\prime} 50^{\prime \prime}$ \\
\hline 148 & 29 & Plataforma média & $12^{\circ} 35^{\prime} 58^{\prime \prime}$ & $3758^{\prime} 57^{\prime \prime}$ \\
\hline 149 & 30 & Plataforma média & $12^{\circ} 32^{\prime} 01^{\prime \prime}$ & $37^{\circ} 56^{\prime} 41^{\prime \prime}$ \\
\hline 165 & 32 & Plataforma média & $12^{\circ} 04^{\prime} 16^{\prime \prime}$ & $37^{\circ} 32^{\prime} 25^{\prime \prime}$ \\
\hline 130 & 32,5 & Plataforma média & $12^{\circ} 59^{\prime} 37^{\prime \prime}$ & $38^{\circ} 24^{\prime} 32^{\prime \prime}$ \\
\hline 120 & 36,3 & Plataforma média & $13^{\circ} 08^{\prime} 19^{\prime \prime}$ & $3834^{\prime} 58^{\prime \prime}$ \\
\hline 129 & 37 & Plataforma média & $13^{\circ} 02^{\prime} 45^{\prime \prime}$ & 38 o $28^{\prime} 04^{\prime \prime}$ \\
\hline 157 & 39 & Plataforma média & $12^{\circ} 23^{\prime} 10^{\prime \prime}$ & $37044^{\prime} 38^{\prime \prime}$ \\
\hline 134 & 40 & Plataforma média & $12^{\circ} 52^{\prime} 56^{\prime \prime}$ & $38^{\circ} 14^{\prime} 13^{\prime \prime}$ \\
\hline 142 & 43 & Plataforma externa & $12^{\circ} 45^{\prime} 27^{\prime \prime}$ & $37^{\circ} 00^{\prime} 28^{\prime \prime}$ \\
\hline 139 & 44 & Plataforma externa & $12^{\circ} 48^{\prime} 07^{\prime \prime}$ & 38 o $04^{\prime} 40^{\prime \prime}$ \\
\hline 145 & 44 & Plataforma externa & $12^{\circ} 41^{\prime} 53^{\prime \prime}$ & 38 을 $38^{\prime \prime}$ \\
\hline 158 & 44 & Plataforma externa & $12^{\circ} 23^{\prime} 28^{\prime \prime}$ & $3740^{\prime} 44^{\prime \prime}$ \\
\hline 159 & 47 & Plataforma externa & $12^{\circ} 20^{\prime} 17^{\prime \prime}$ & $37^{\circ} 37^{\prime} 42^{\prime \prime}$ \\
\hline 140 & 48 & Plataforma externa & $12^{\circ} 49^{\prime} 56^{\prime \prime}$ & 38 o $01^{\prime} 24^{\prime \prime}$ \\
\hline 167 & 49 & Plataforma externa & $12^{\circ} 59^{\prime} 15^{\prime \prime}$ & $37^{\circ} 21^{\prime} 05^{\prime \prime}$ \\
\hline 137 & 50 & Plataforma externa & $12^{\circ} 51^{\prime} 21^{\prime \prime}$ & $38^{\circ} 09^{\prime} 24^{\prime \prime}$ \\
\hline 152 & 51 & Plataforma externa & $12^{\circ} 29^{\prime} 50^{\prime \prime}$ & $37^{\circ}=50^{\prime} 46^{\prime \prime}$ \\
\hline 150 & 57 & Plataforma externa & $12^{\circ} 34^{\prime} 57^{\prime \prime}$ & $37^{\circ} 52^{\prime} 35^{\prime \prime}$ \\
\hline 128 & 60 & Plataforma externa & $1304^{\prime} 56^{\prime \prime}$ & $3826^{\prime} 58^{\prime \prime}$ \\
\hline 166 & 80 & Talude & $12^{\circ} 05^{\prime} 15^{\prime \prime}$ & $37^{\circ} 27^{\prime} 14^{\prime \prime}$ \\
\hline 146 & 120 & Talude & $12^{\circ} 43^{\prime} 30^{\prime \prime}$ & $37^{\circ} 55^{\prime} 35^{\prime \prime}$ \\
\hline 131 & 150 & Talude & $13^{\circ}$ "02' $20^{\prime \prime}$ & $38^{\circ} 20^{\prime} 46^{\prime \prime}$ \\
\hline 127 & 190 & Talude & $13^{\circ} 07^{\prime} 07^{\prime \prime}$ & $38^{\circ} 26^{\prime} 07^{\prime \prime}$ \\
\hline 121 & 218,5 & Talude & $13^{\circ}$ - $11^{\prime} 04^{\prime \prime}$ & $38^{\circ} 33^{\prime} 15^{\prime \prime}$ \\
\hline 135 & 300 & Talude & $12^{\circ} 58^{\prime} 22^{\prime \prime}$ & $38^{\circ}$ o $11^{\prime} 35^{\prime \prime}$ \\
\hline
\end{tabular}

\subsection{Análises sedimentológicas}

As amostras foram secas, pesadas, homogeneizadas com água destilada e posteriormente passadas através de uma peneira com espaçamento de malha de $0,062 \mathrm{~mm}$ para eliminação dos sais e separação da fração lama. Em seguida, a fração retida e secada a $60^{\circ} \mathrm{C}$ foi peneirada segundo a escala granulométrica de Wentworth (1962), com intervalo de um phi. A fração lama, quando presente, foi colocada para secar a $40^{\circ} \mathrm{C}$ e pesada. 0 tipo de sedimento de cada amostra foi determinado segundo a nomenclatura proposta por Shepard (1954), que apresenta um esquema classificativo puramente descritivo, não existindo preocupações em viabilizar deduções de características hidrodinâmicas do ambiente de deposição. Nesse esquema existem três classes correspondentes à componente dominante, ou seja, componente com percentagem superior a $75 \%$. A designação da classe corresponde à componente dominante: areia, silte e argila. Nas outras seis classes existem misturas de dois componentes e recebem a deno- minação do componente dominante adjetivado pelo do componente secundário: areia siltosa, argila arenosa, argila siltosa, silte argiloso, silte arenoso e areia argilosa. Schlee (1973) modificou o esquema de Shepard (1954) complementando-o com um segundo diagrama ternário em que o componente cascalho é valorizado, passando a poder ser aplicado a todos os tipos de sedimentos.

Para a análise da composição do sedimento, 300 grãos de cada amostra foram identificados com o auxílio de microscópio estereoscópio (lupa binocular) e multiplicados pelo peso da amostra para obtenção dos percentuais de cada componente. A classificação do sedimento segundo a composição carbonática e/ou siliciclástica foi de acordo com a classificação apresentada por Testa (1996) sendo: sedimento siliciclástico (possui teores de grãos carbonáticos inferiores a $40 \%$ ), sedimento misto (teores de grãos carbonáticos entre 40 e $60 \%$ ), e sedimento carbonático (teores de grãos carbonáticos superiores a $60 \%$ ). 


\subsection{Análise da fauna de foraminíferos}

De cada amostra de superfície do fundo extraiu-se $10 \mathrm{~cm}^{3}$ de material que foi lavado em água destilada através de uma peneira com espaçamento de malha 0,062 mm para eliminação dos sais e separação da fração lama. Em seguida colocou-se o material para secar em estufa a $50^{\circ} \mathrm{C}$, e, posteriormente, pesado e quarteado. Após, foram separadas, aleatoriamente, as 300 primeiras testas de foraminíferos, para identificação das espécies, através de lupa binocular.

Esta metodologia descrita por Drooger \& Kaasschietter (1958) é considerada adequada quando se utiliza grande número de amostras e se deseja realizar tratamento estatístico (Araújo \& Araújo, 2010). Os espécimes foram identificados segundo Loeblich \& Tappan (1988) e publicações de foraminíferos recentes: Araújo \& Machado (2008a,b,c) e Eichler et al. (2012).

Exemplares de foraminíferos, que apresentaram melhor grau de conservação, foram fotografados em microscópio eletrônico de varredura (MEV).

\subsection{Tratamento estatístico}

Considerando os 300 espécimes identificados em cada amostra, foi calculada a quantidade de indivíduos por espécie. A partir desses dados de abundância absoluta das espécies foram confeccionadas matrizes básicas de dados, aplicando a metodologia proposta por Dajoz (1983), Clarke \& Warwick (1994) e Ab'Saber et al. (1997).

\section{Frequência de ocorrência (constância das espécies)}

Consiste no número de amostras que contêm a espécie $(p)$ em relação ao número total de amostras analisadas (P) Ab'Saber et al. (1997). Esta frequência foi calculada pela fórmula 1 :

$$
F O=\frac{p x 100}{P}
$$

Após estes cálculos, as espécies foram agrupadas em três categorias de acordo com a classificação de Dajoz (1983), sendo definidas como constantes (as espécies presentes em mais de $50 \%$ das amostras); acessórias (que ocorrem entre $25 \%$ a $49 \%$ das amostras) e acidentais (presentes em menos de $25 \%$ das amostras).

\section{Frequência relativa (abundância das espécies)}

Consiste na razão entre o número total de indivíduos de uma categoria obtido na amostra $(n)$ e o total de indivíduos de todas as categorias $(T)$ na amostra, expresso em percentagem (Ab'Saber et al., 1997), conforme fórmula 2.
$F R=\frac{n x 100}{T}$

Este critério determina as espécies abundantes em cada amostra. Os resultados permitiram classificar as espécies, de acordo com critérios de classificação de Dajoz (1983), em principais (frequência acima de $5 \%$ ); acessória (entre 5 e $1 \%$ ) e traço (inferior a $1 \%$ ).

\section{Análise de agrupamento}

Devido à grande quantidade de espécies encontradas na área de estudo, para aplicar a análise multivariada foi realizado um levantamento das espécies que possuem, ao mesmo tempo, frequência de ocorrência maior que 50 \% (constantes) e abundância relativa maior que $5 \%$ (principais) em pelo menos duas amostras. Estes critérios foram anteriormente utilizados por Araújo (2004), Bruno (2008) e Araújo \& Araújo (2010). Dessa forma, as espécies raras e as espécies que não têm representação gráfica foram eliminadas.

A análise de agrupamento foi aplicada, visando adequar uma técnica multivariada para estudos envolvendo grande número de amostras e espécies, com o objetivo de medir o grau de similaridade entre os objetos estudados e reuni-los em um mesmo grupo. Os dados originais foram padronizados para assegurar que as variáveis sejam igualmente importantes na determinação do grau de similaridade entre os objetos, permitindo que os resultados obtidos apresentassem maior confiabilidade.

A técnica de agrupamento hierárquico interliga as amostras ou espécies por suas associações, produzindo um dendrograma (gráfico). A suposição básica de sua interpretação é que quanto menor a distância entre os pontos, maior a semelhança entre as amostras.

Os dados foram submetidos a diferentes métodos de agrupamento hierárquicos para decidir o mais adequado para o desenvolvimento do trabalho. Para os diversos métodos de agrupamento utilizados foram obtidas, após a construção dos dendrogramas, as respectivas matrizes cofenéticas resultantes da simplificação proporcionada pelo método.

Para avaliar a consistência dos agrupamentos obtidos, ou seja, verificar a capacidade do dendrograma em reproduzir a matriz de dissimilaridade, calculou-se o coeficiente de correlação cofenética. Esse índice compara as distâncias efetivamente observadas entre os objetos e as distâncias previstas a partir do processo de agrupamento, medindo o grau de ajuste entre a matriz de dissimilaridade original e a matriz de dissimilaridade produzida após a construção do dendrograma (matriz cofenética).

0 coeficiente de correlação cofenética permite avaliar o grau de deformação provocado pela construção do dendrograma e o menor grau de distorção será definido pelo maior valor desse coeficiente. Segundo Bussab et al. (1990), quanto mais próximo da unida- 
de estiver esse índice de correlação cofenética melhor será a representação do dendrograma. Segundo estes autores, a correlação cofenética é dada pela fórmula 3.

$$
r_{c o f}=\frac{\sum_{i=1}^{n-1} \sum_{j=i+1}^{n}\left(c_{i j-} \bar{c}\right)\left(d_{i j-} \bar{d}\right)}{\sqrt{\sum_{i=1}^{n-1} \sum_{j=i+1}^{n}\left(c_{i j-}-\bar{c}\right)^{2}} \sqrt{\sum_{i=1}^{n-1} \sum_{j=i+1}^{n}\left(d_{i j-} \bar{d}\right)^{2}}}
$$

Em que:

$c_{i j}=$ valor de dissimilaridade entre os objetos i e j, obtidos pela matriz cofenética.

$d_{i j}=$ valor de dissimilaridade entre os objetos i e j, obtidos pela matriz de dissimilaridade original.

$$
\begin{gathered}
\bar{c}=\frac{2}{n(n-1)} \sum_{i=1}^{n-1} \sum_{j=i+1}^{n} c_{i j}, \\
\bar{d}=\frac{2}{n(n-1)} \sum_{i=1}^{n-1} \sum_{j=i+1}^{n} d_{i j},
\end{gathered}
$$

Portanto, um método é melhor do que o outro, quando o dendrograma fornecer uma imagem menos distorcida da realidade.

0 método de Ward foi aplicado nesse trabalho porque obteve o maior coeficiente de correlação cofenética, apresentando o melhor resultado em relação aos outros métodos utilizados. Muitos estudos mostraram que, de maneira geral, o método de Ward possui melhor desempenho (Rencher, 2002).

Esse método hierárquico, às vezes chamado de método de variância mínima, está fundamentado na análise de variância e busca juntar dois grupos cuja fusão minimiza a soma de quadrados dentro dos grupos, ou seja, a soma de quadrados dos erros (isto é, a variância mínima dentro do grupo) (Lattin et al., 2011). A cada passo do processo de análise, as amostras ou espécies que apresentaram padrões similares são agrupadas de acordo com uma medida de dissimilaridade, definida nesse trabalho pela distância euclidiana ao quadrado. Ferreira (2008) recomenda utilizar a distância euclidiana quadrática ao aplicar o método de Ward, que é norteado pelas seguintes ideias: Inicialmente, têm-se tantos grupos quantos objetos, ou seja, temos $n$ grupos com 1 objeto cada. Agrupam-se, no primeiro ciclo do algoritmo, os dois grupos, de um único objeto cada, que minimizam o incremento na soma de quadrados dos erros em relação ao estágio anterior. É conveniente ter a noção clara que ao aglomerar dois grupos, a soma de quadrados dos erros irá aumentar. 0 que irá se buscar é o par de grupos que provocará o menor incremento possível na soma de quadrados dos erros entre todos os possíveis pares. Ao aglomerar os grupos que atendem à função objetivo, minimizar o incremento na soma de quadrados dos erros, deve-se atualizar a matriz de dissimilaridades e então repetir o processo.

Segundo Rencher (2002), se $A B$ é um grupo obtido pela combinação dos grupos $A$ e $B$, então a soma das distâncias dentro do grupo (dos elementos a partir do vetor de média dos grupos) são $S S E_{A}$ (a soma de quadrados relativa ao grupo $A$ ), $S S E_{B}$ (a soma de quadrados relativa ao grupo $B$ ) e $S S E_{A B}$ (a soma de quadrados relativa ao grupo $A B$ ), em que:

$\operatorname{SSE} E_{A}=\sum_{i=1}^{n_{A}}\left(y_{i A}-\bar{y}_{A}\right)^{\prime}\left(y_{i A}-\bar{y}_{A}\right)$

sendo $y_{i A}=\left(y_{i 1 A}, y_{i 2 A}, \ldots, y_{i k A}\right)^{\prime} \quad$ o vetor de observações do elemento amostral $i$ pertencente ao grupo $A$, $\bar{y}_{A}=\left(\bar{y}_{1 A}, \bar{y}_{2 A}, \ldots, \bar{y}_{k A}\right)^{\prime}$ o vetor de médias amostrais do grupo $A, i=1,2, \ldots, k$, sendo $k$ o número de variáveis e $n_{A}$ o número de elementos amostrais do grupo $A$.

$$
S S E_{B}=\sum_{i=1}^{n_{B}}\left(y_{i B}-\bar{y}_{B}\right)^{\prime}\left(y_{i B}-\bar{y}_{B}\right)
$$

sendo $y_{i B}=\left(y_{i 1 B}, y_{i 2 B}, \ldots, y_{i k B}\right)^{\prime}$ o vetor de observações do elemento amostral $i$ pertencente ao grupo B, $\bar{y}_{B}=\left(\bar{y}_{1 B}, \bar{y}_{2 B}, \ldots, \bar{y}_{k B}\right)^{\prime}$ o vetor de médias amostrais do grupo $B, i=1,2, \ldots, k$, sendo $k$ o número de variáveis e $n_{B} 0$ número de elementos amostrais do grupo $B$.

$$
S S E_{A B}=\sum_{i=1}^{n_{A B}}\left(y_{i A B}-\bar{y}_{A B}\right)^{\prime}\left(y_{i A B}-\bar{y}_{A B}\right)
$$

sendo $y_{i A B}=\left(y_{i 1 A B}, y_{i 2 A B}, \ldots, y_{i k A B}\right)$ o vetor de observações do elemento amostral $i$ pertencente ao grupo $A B, A B, \bar{y}_{A B}=\left(\bar{y}_{1 A B}, \bar{y}_{2 A B}, \ldots, \bar{y}_{k A B}\right)^{\prime} \mathrm{o}$ vetor de médias amostrais do grupo $A B, l=1,2, \ldots, k$, sendo $k$ o número de variáveis e $n_{A B}$ o número de elementos amostrais do grupo $A B$.

$$
\bar{y}_{A B}=\frac{\left(n_{A} \bar{y}_{A}+n_{B} \bar{y}_{B}\right)}{n_{A} n_{B}}
$$

Em que, $n_{A^{\prime}} n_{B}$ e $n_{A B}=n_{A}+n_{B}$ são o número de pontos em $A, B$ e $A B$, respectivamente. Então, as somas das distâncias são equivalentes à soma de quadrados dentro dos grupos, denotadas por $S S E_{A}, S S E_{B}$ e $S S E_{A B}$.

0 método de Ward une dois grupos $A$ e $B$ que minimizam o acréscimo em SSE, definido como

$$
I_{A B}=S S E_{A B}-\left(S S E_{A}+\operatorname{SSE}{ }_{B}\right)
$$

Conforme Rencher (2002) pode-se demonstrar que $I_{A B}$ em (10) possui duas formas equivalentes:

$$
\begin{aligned}
& I_{A B}=n_{A}\left(\bar{y}_{A-} \bar{y}_{A B}\right)^{\prime}\left(\bar{y}_{A-} \bar{y}_{A B}\right)+n_{B}\left(\bar{y}_{B-} \bar{y}_{A B}\right)^{\prime}\left(\bar{y}_{B-} \bar{y}_{A B}\right) \\
& I_{A B}=\frac{n_{A} n_{B}}{n_{A}+n_{B}}\left(\bar{y}_{A}-\bar{y}_{B}\right)^{\prime}\left(\bar{y}_{A}-\bar{y}_{B}\right)
\end{aligned}
$$


Assim, por (12) minimizar o aumento na SSE é equivalente a minimizar a distância entre grupos. Se $A$ e $B$ possuem apenas um elemento $y_{i}$ e $y_{i}$, respectivamente, então $S S E_{A}=0$ e $S S E_{B}=0$, e (11) e (12) reduz a:

$I_{i j}=I_{A B}=S S E_{A B}=\frac{1}{2}\left(\bar{y}_{A}-\bar{y}_{B}\right)^{\prime}\left(\bar{y}_{A}-\bar{y}_{B}\right)=\frac{1}{2} d^{2}\left(y_{i}, y_{j}\right)$

O método de Ward é apropriado apenas para variáveis quantitativas e sua aplicação não depende de que os dados sejam provenientes ou não de uma distribuição normal multivariada (Mingoti, 2005).

Para validar os agrupamentos obtidos pelo método de Ward foi aplicado o método não hierárquico k-Médias, que utilizou como sementes iniciais os vetores de médias de cada grupo (centróides) formado pelo método de Ward. Segundo Bussab et al. (1990), o método de partição k-Médias fornece indicações mais precisas sobre o número de grupos a ser formado e talvez seja um dos mais utilizados quando se têm muitos objetos para agrupar, com pequenas variações. 0 critério de homogeneidade dentro do grupo e heterogeneidade entre grupos é a soma de quadrados residual baseado na análise de variância. Assim, quanto menor for este valor, mais homogêneos são os elementos dentro de cada grupo e melhor será a partição.

Para avaliar o grau de homogeneidade dentro de cada grupo, calculou-se o coeficiente $R^{2}$ da partição definido por:

$$
R^{2}=\frac{S S B}{S S T_{c}}
$$

Em que:

$S S B$ = a soma de quadrados total entre os grupos de partição.

$S S T_{c}$ = a soma de quadrados total corrigida para a média global de cada variável.

Quanto maior for o valor de $R^{2}$, maior será a soma de quadrados entre grupos e menor será o valor da soma de quadrados residual. 0 coeficiente $R^{2}$ cujo valor máximo alcançado é igual a 1 pode ser utilizado como critério para determinar o número de grupos da partição final (Mingoti, 2005).

Foi realizada uma análise de agrupamento entre espécies (modo R) com padrões similares, segundo as amostras (localizações) que as contém. A variável corresponde ao número de indivíduos (frequência absoluta) de cada espécie nas diferentes localizações. Esse tipo de análise foi realizada para as plataformas interna, média, externa e o talude.

Na plataforma interna foi realizada uma análise da associação entre as frequências absolutas (FA) das 11 espécies de foraminíferos para cada uma das 5 localizações, obtendo uma matriz de informação do tipo 11 x 5 . Na plataforma média foi aplicada uma análise de agrupamento entre as frequências absolutas (FA) das 18 espécies de foraminíferos para cada uma das 16 locali- zações (amostras), obtendo uma matriz de informação do tipo $18 \times 16$. Na plataforma externa realizou-se uma análise da associação entre as frequências absolutas (FA) das 13 espécies de foraminíferos para cada uma das 11 localizações (amostras), obtendo uma matriz de informação do tipo $13 \times 11$. No talude foi realizada uma análise da associação entre as frequências absolutas (FA) das 10 espécies de foraminíferos para cada uma das 6 localizações (amostras), obtendo uma matriz de informação do tipo $10 \times 6$.

Em seguida, foi aplicada uma análise de agrupamento entre as amostras (modo Q) segundo os teores sedimentológicos de cada amostra. Nessa análise, foram consideradas 38 amostras e 5 variáveis: teor de carbonato (\%) teor de siliciclasto (\%), areia (\%), lama (\%) e cascalho (\%), obtendo uma matriz de informação do tipo $38 \times 5$. Toda a análise estatística foi realizada utilizando-se programas e bibliotecas que estão disponíveis no software $\mathrm{R}$ ( $R$ Development Core Team, 2012).

\section{Resultados}

0 dendrograma apresentado na figura 2 representa a análise de agrupamento entre as 11 espécies (modo R) da plataforma interna, considerando as cinco amostras (localizações) que as contém. 0 coeficiente de correlação cofenética foi igual a 0,97 . No dendrograma, o corte foi estabelecido na distância 12,7 e foram definidos quatro grupos: A, B, C e D.

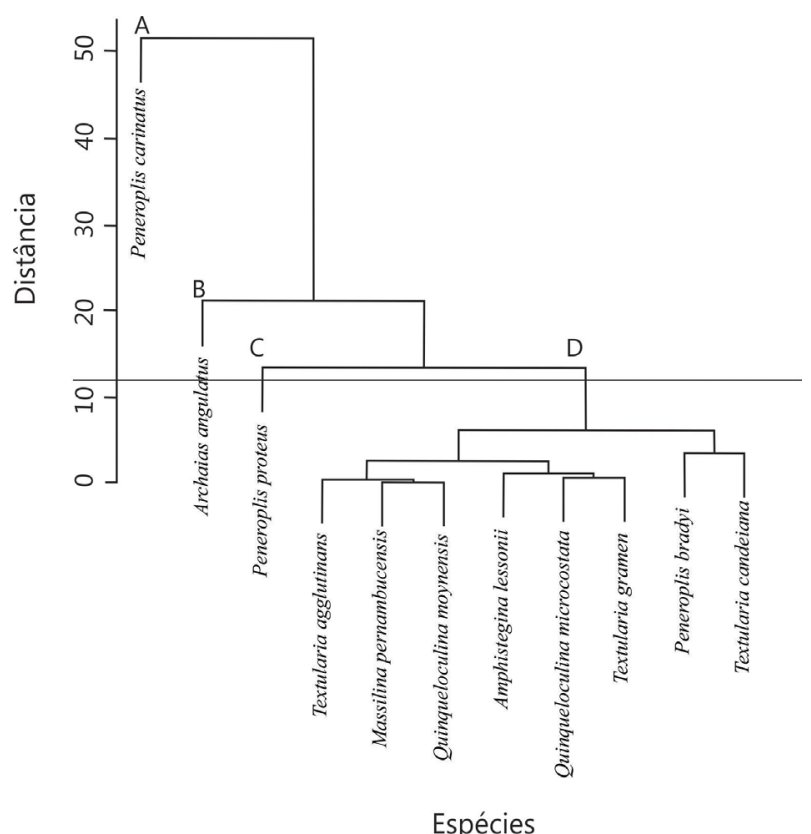

Figura 2. Dendrograma do Método de Ward com base na distância euclidiana quadrática agrupando as espécies da plataforma interna, a partir das amostras (localização).

No Grupo A foi individualizada a espécie Peneroplis carinatus, que apresentou, em média, 49 indivíduos neste grupo e elevada abundância (frequência absoluta) nas diferentes localidades (amostras). A maior abundância desta espécie foi encontrada na amostra 
156 (107 espécimes) e a menor abundância na amostra 123 (5 espécimes). 0 Grupo B isolou a espécie Archaias angulatus que obteve, em média, 20,4 indivíduos neste grupo. A maior abundância desta espécie foi observada na amostra 123 (75 indivíduos) e a menor abundância na amostra 124 (3 indivíduos). O Grupo C individualizou a espécie Peneroplis proteus que apresentou, em média, 21 indivíduos neste grupo. A abundância elevada foi evidenciada na amostra 125 (67 indivíduos) e abundância reduzida na amostra 123 (2 indivíduos). 0 Grupo D foi formado pelas demais espécies. A média de indivíduos neste grupo variou de 5,2 a 12,2.

0 Grupo A foi caracterizado por apresentar maior abundância da espécie Peneroplis carinatus na plataforma interna (245 indivíduos). Os Grupos B e C apresentaram, respectivamente, as espécies Archaias angulatus e Penerolopis proteus como as mais abundantes, ambas apresentando mais de 100 espécimes nas amostras de plataforma interna. No Grupo D foram reunidas as espécies com o máximo de 61 e mínimo de 26 indivíduos (Tab. 2 e 3).

Tabela 2. Número de indivíduos das espécies da plataforma interna.

\begin{tabular}{|c|c|c|c|c|c|c|}
\hline Espécies /Amostras & 123 & 124 & 125 & 156 & 164 & Total \\
\hline Amphistegina lessonii & 10 & 5 & 15 & 2 & 5 & 37 \\
\hline Archaias angulatus & 75 & 3 & 10 & 4 & 10 & 102 \\
\hline Massilina pernambucensis & 1 & 8 & 4 & 5 & 18 & 36 \\
\hline Peneroplis bradyi & 2 & 22 & 17 & 7 & 12 & 60 \\
\hline Peneroplis carinatus & 5 & 36 & 55 & 107 & 42 & 245 \\
\hline Peneroplis proteus & 2 & 6 & 67 & 19 & 11 & 105 \\
\hline Quinqueloculina microcostata & 3 & 5 & 15 & 10 & 16 & 49 \\
\hline Quinqueloculina moynensis & 0 & 6 & 3 & 0 & 17 & 26 \\
\hline Textularia agglutinans & 1 & 7 & 5 & 17 & 19 & 49 \\
\hline Textularia candeiana & 0 & 17 & 3 & 12 & 29 & 61 \\
\hline Textularia gramen & 0 & 9 & 16 & 12 & 10 & 47 \\
\hline
\end{tabular}

Tabela 3. Medidas descritivas dos agrupamentos de espécies encontrados na plataforma interna pelo método de Ward. FA= frequência absoluta.

\begin{tabular}{|c|c|c|c|c|c|c|c|c|}
\hline \multirow[t]{2}{*}{ Variáveis (FA) } & \multicolumn{2}{|l|}{ Grupo A } & \multicolumn{2}{|l|}{ Grupo B } & \multirow{2}{*}{$\begin{array}{c}\text { Grupo C } \\
\text { Média }\end{array}$} & \multicolumn{3}{|c|}{ Grupo D } \\
\hline & Média & $\begin{array}{l}\text { Desvio } \\
\text { Padrão }\end{array}$ & Média & $\begin{array}{l}\text { Desvio } \\
\text { Padrão }\end{array}$ & & $\begin{array}{l}\text { Desvio } \\
\text { Padrão }\end{array}$ & Média & $\begin{array}{l}\text { Desvio } \\
\text { Padrão }\end{array}$ \\
\hline Amphistegina lessonii & & & & & & & 7,4 & 5,13 \\
\hline Archaias angulatus & & & 20,4 & 30,70 & & & & \\
\hline Massilina pernambucensis & & & & & & & 7,2 & 6,53 \\
\hline Peneroplis bradyi & & & & & & & 12,0 & 7,91 \\
\hline Peneroplis carinatus & 49,0 & 37,26 & & & & & & \\
\hline Peneroplis proteus & & & & & 21 & 26,49 & & \\
\hline Quinqueloculina microcostata & & & & & & & 9,8 & 5,81 \\
\hline Quinqueloculina moynensis & & & & & & & 5,2 & 7,05 \\
\hline Textularia agglutinans & & & & & & & 9,8 & 7,82 \\
\hline Textularia candeiana & & & & & & & 12,2 & 11,61 \\
\hline Textularia gramen & & & & & & & 9,4 & 5,90 \\
\hline
\end{tabular}

0 método k-Médias foi aplicado utilizando-se como sementes iniciais os quatro grupos formados pelo método de Ward. Observou-se que as 11 espécies da plataforma interna foram classificadas nos mesmos agrupamentos pelos dois métodos. 0 coeficiente $R^{2}$ obtido foi $85,8 \%$, indicando que os grupos encontrados são homogêneos internamente.

A figura 3 apresenta o dendrograma obtido da análise de agrupamento entre as 18 espécies da plataforma média, considerando 16 amostras (localizações). 0 valor do índice de correlação cofenética obtido para essa associação de espécies correspondeu a 0,93. 0 corte no dendrograma foi estabelecido na distância 50 onde foram definidos cinco grupos: A, B , C , D e E.

O Grupo A isolou a espécie Peneroplis carinatus que apresentou, em média, 41,1 indivíduos neste gru- po e maior abundância absoluta na amostra $144(142$ espécimes). Esta espécie foi a mais frequente da plataforma média (658 indivíduos). 0 Grupo B reuniu as espécies com abundância absoluta entre 50 e 103 espécimes e a média de indivíduos neste grupo variou entre 3,1 e 6,4 (Hanzawaia bertheloti e Quinqueloculina bicarinata, respectivamente). 0 Grupo $\mathrm{C}$ agregou as demais espécies, com abundâncias entre 41 e 149 indivíduos. A média de indivíduos neste grupo variou de 2,6 a 9,2. No Grupo D foi individualizada a espécie Peneroplis bradyi, com 256 espécimes. Neste grupo, a média de indivíduos foi 41,1 . Na amostra 129 foi observada a maior abundância absoluta desta espécie (47 espécimes) e na amostra 155 a menor (2 espécimes). No Grupo E foram agrupadas duas espécies do mesmo gênero Amphistegina gibbosa (238 espécimes) e A. les- 
sonii (273 espécimes). As médias de indivíduos encontradas neste grupo foram 14,9 e 17,1, respectivamente (Tab. 4 e 5).

Utilizando como sementes iniciais os cinco grupos formados pelo método de Ward, aplicou-se o método k-Médias e foi possível observar que as 18 espécies da plataforma média foram classificadas nos mesmos agrupamentos pelos dois métodos. 0 coeficiente $R^{2}$ obtido foi $80 \%$, indicando que os grupos encontrados são homogêneos internamente.

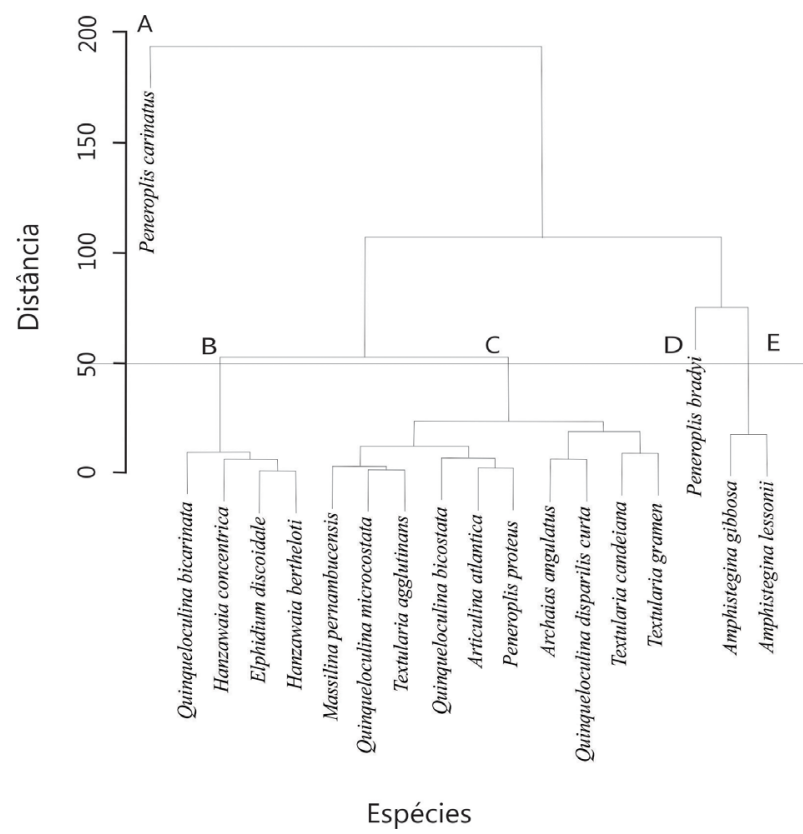

Figura 3. Dendrograma do Método de Ward com base na distância euclidiana quadrática agrupando as espécies da plataforma média, a partir das amostras (localização).

Na figura 4 observa-se o dendrograma correspondente à análise de agrupamento entre as 13 espécies da plataforma externa, considerando 11 amostras (localizações) que as encerram. O valor do índice de correlação cofenética obtido para essa associação de espécies correspondeu a 0,87. Estabelecendo o corte na distância de 18,3 foram definidos seis grupos: A, B, C, D, E e F.

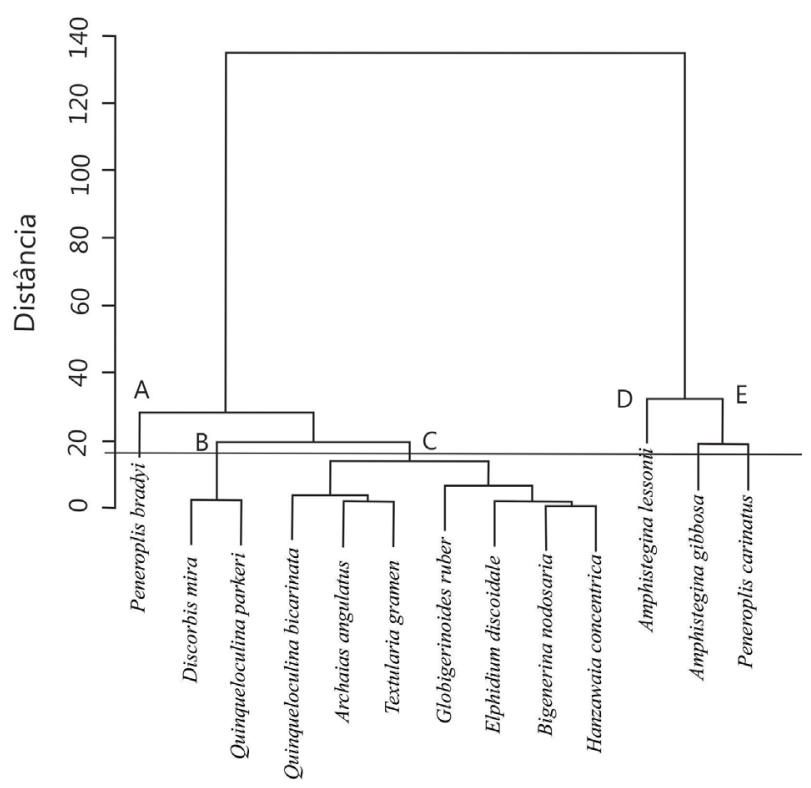

Espécies

Figura 4. Dendrograma do Método de Ward com base na distância euclidiana quadrática agrupando as espécies da plataforma externa, a partir das amostras (localização).

O Grupo A individualizou a espécie Peneroplis bradyi, com 147 espécimes. Neste grupo, a média de indivíduos correspondeu a 13,4. Na amostra 128 foi observada a maior abundância absoluta desta espécie (43 indivíduos) e na amostra 158 a menor (1 indivíduo). O Grupo B reuniu as espécies Quinqueloculina parkere

Tabela 4. Número de indivíduos das espécies da plataforma média.

\begin{tabular}{|c|c|c|c|c|c|c|c|c|c|c|c|c|c|c|c|c|c|}
\hline Espécies / Amostras & 120 & 129 & 130 & 133 & 134 & 138 & 143 & 144 & 148 & 149 & 154 & 155 & 157 & 161 & 163 & 165 & Total \\
\hline Amphistegina gibbosa & 2 & 11 & 0 & 66 & 0 & 45 & 20 & 0 & 1 & 22 & 29 & 0 & 29 & 8 & 2 & 3 & 238 \\
\hline Amphistegina lessonii & 7 & 13 & 3 & 40 & 3 & 9 & 14 & 6 & 5 & 18 & 50 & 15 & 38 & 25 & 6 & 21 & 273 \\
\hline Archaias angulatus & 6 & 5 & 0 & 10 & 0 & 37 & 16 & 6 & 1 & 17 & 7 & 1 & 5 & 9 & 7 & 20 & 147 \\
\hline Articulina atlantica & 2 & 3 & 2 & 1 & 0 & 3 & 3 & 24 & 12 & 4 & 0 & 5 & 0 & 2 & 8 & 10 & 79 \\
\hline Elphidium discoidale & 6 & 7 & 10 & 1 & 18 & 0 & 0 & 1 & 2 & 1 & 2 & 3 & 3 & 1 & 2 & 5 & 62 \\
\hline Hanzawaia bertheloti & 4 & 1 & 9 & 0 & 19 & 0 & 0 & 0 & 2 & 3 & 7 & 0 & 3 & 1 & 0 & 1 & 50 \\
\hline Hanzawaia concentrica & 20 & 7 & 6 & 2 & 17 & 0 & 0 & 0 & 3 & 2 & 2 & 2 & 0 & 1 & 0 & 0 & 62 \\
\hline Massilina pernambucensis & 0 & 0 & 0 & 8 & 0 & 0 & 1 & 1 & 1 & 0 & 2 & 16 & 0 & 8 & 16 & 1 & 54 \\
\hline Peneroplis bradyi & 30 & 47 & 18 & 9 & 5 & 6 & 12 & 29 & 19 & 21 & 5 & 2 & 12 & 10 & 14 & 17 & 256 \\
\hline Peneroplis carinatus & 5 & 12 & 2 & 40 & 0 & 102 & 96 & 142 & 55 & 22 & 11 & 60 & 13 & 22 & 26 & 50 & 658 \\
\hline Peneroplis proteus & 2 & 4 & 0 & 4 & 0 & 11 & 9 & 33 & 2 & 6 & 2 & 9 & 1 & 3 & 3 & 2 & 91 \\
\hline Quinqueloculina bicarinata & 8 & 5 & 8 & 9 & 10 & 6 & 5 & 2 & 5 & 3 & 9 & 2 & 3 & 16 & 7 & 5 & 103 \\
\hline Quinqueloculina bicostata & 2 & 4 & 2 & 3 & 2 & 2 & 0 & 0 & 1 & 20 & 2 & 1 & 0 & 1 & 0 & 1 & 41 \\
\hline Quinqueloculina disparilis curta & 10 & 16 & 2 & 6 & 1 & 3 & 7 & 2 & 2 & 13 & 17 & 2 & 10 & 15 & 1 & 11 & 118 \\
\hline Quinqueloculina microcostata & 1 & 1 & 0 & 1 & 1 & 5 & 15 & 7 & 3 & 2 & 4 & 6 & 1 & 2 & 16 & 7 & 72 \\
\hline Textularia agglutinans & 1 & 2 & 0 & 0 & 1 & 2 & 3 & 1 & 6 & 2 & & 5 & 0 & 0 & 25 & 1 & 49 \\
\hline Textularia candeiana & 7 & 6 & 9 & 2 & 3 & 5 & 8 & 3 & 13 & 8 & 5 & 14 & 2 & 6 & 33 & 9 & 133 \\
\hline Textularia gramen & 12 & 17 & 4 & 13 & 3 & 7 & 7 & 3 & 3 & 9 & 15 & 21 & 11 & 4 & 15 & 5 & 149 \\
\hline
\end{tabular}


(44 espécimes) e Discorbis mira (92 espécimes). As médias de indivíduos encontradas neste grupo foram 4,9 e 9,2, respectivamente. 0 Grupo C foi constituído de 7 espécies: Quinqueloculina bicarinata (104 indivíduos), Textularia gramem (98 indivíduos), Globigerinoides ruber (96 indivíduos), Archaias angulatus (71 indivíduos), Elphidium discoidale (49 indivíduos), Bigenerina nodosaria (49 indivíduos) e Hanzawaia concentrica (32 indivíduos). A média de indivíduos neste grupo variou de 5,3 a 9,5. 0 Grupo D isolou a espécie Amphistegina lessonii, a qual apresentou maior abundância na plataforma externa, ou seja, 375 indivíduos. Neste grupo, a maior abundância desta espécie (87 indivíduos) foi encontrada na amostra 150 e a menor abundância (1 indivíduo) na amostra 152. A média de indivíduos neste grupo correspondeu a 34,1. 0 Grupo E individualizou a espécie Amphistegina gibbosa com 280 espécimes. Neste grupo, a média de indivíduos foi 25,5 . Na amostra 142 observou-se a maior abundância desta espécie (51 indivíduos) e na amostra 158 a menor abundância (7 indivíduos). 0 grupo $\mathrm{F}$ isolou a espécie $P e$ neroplis carinatus, com 284 indivíduos. Neste grupo, a média de indivíduos foi 25,8. A maior abundância desta espécie foi constatada na amostra 142 (48 indivíduos) e a menor abundância na amostra 150 (4 indivíduos).

0 método k-Médias foi aplicado utilizando-se como sementes iniciais os seis grupos formados pelo método de Ward e ficou evidenciado, que as 13 espécies da plataforma externa foram classificadas nos mesmos agrupamentos pelos dois métodos. 0 coeficiente $R^{2} \mathrm{ob}-$ tido foi $86,5 \%$, indicando que os grupos encontrados são homogêneos internamente (Tab. 6 e 7).

0 dendrograma obtido na figura 5 representa a análise de agrupamento entre as 10 espécies do talude, considerando 6 amostras (localizações) que as contém. 0 valor do índice de correlação cofenética obtido para essa associação de espécies correspondeu a 0,89. 0 corte foi estabelecido na distância 12,5 , sendo definidos quatro grupos: A, B, C e D.

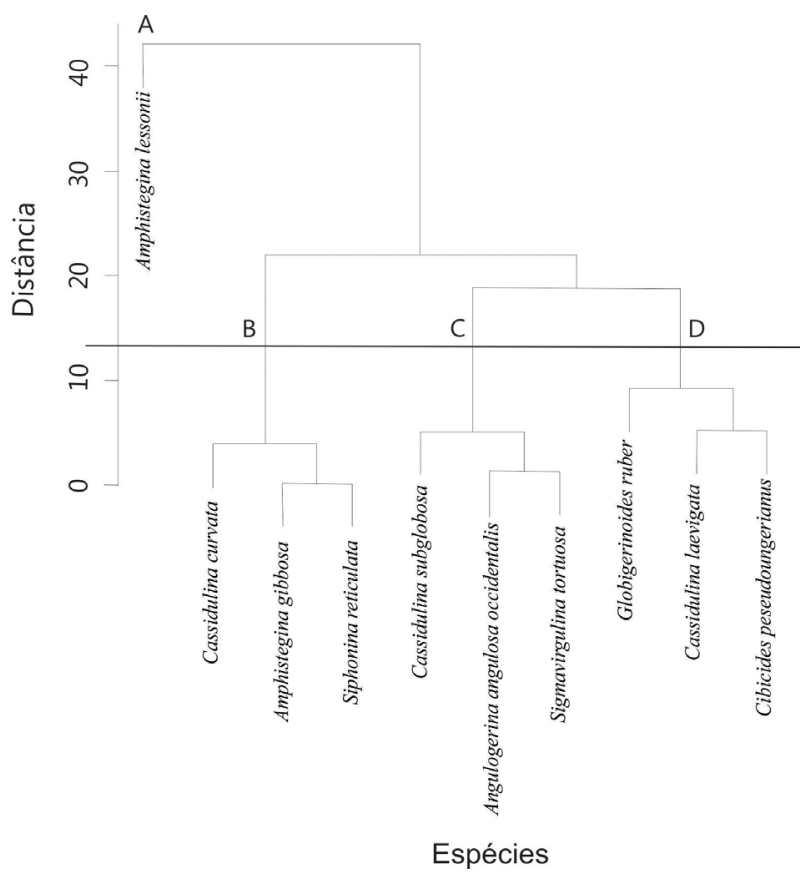

Figura 5. Dendrograma do Método de Ward com base na distância euclidiana quadrática agrupando as espécies do talude, a partir das amostras (localização).

Tabela 5. Medidas descritivas dos agrupamentos de espécies encontrados na plataforma média pelo método de Ward. FA= frequência absoluta.

\begin{tabular}{|c|c|c|c|c|c|c|c|c|c|c|}
\hline \multirow[t]{2}{*}{ Variáveis (FA) } & \multicolumn{2}{|l|}{ Grupo A } & \multicolumn{2}{|l|}{ Grupo B } & \multicolumn{2}{|l|}{ Grupo C } & \multirow{2}{*}{$\begin{array}{c}\text { Grupo D } \\
\text { Média }\end{array}$} & \multicolumn{3}{|c|}{ Grupo E } \\
\hline & Média & $\begin{array}{l}\text { Desvio } \\
\text { Padrão }\end{array}$ & Média & $\begin{array}{l}\text { Desvio } \\
\text { Padrão }\end{array}$ & Média & $\begin{array}{l}\text { Desvio } \\
\text { Padrão }\end{array}$ & & $\begin{array}{l}\text { Desvio } \\
\text { Padrão }\end{array}$ & Média & $\begin{array}{l}\text { Desvio } \\
\text { Padrão }\end{array}$ \\
\hline Amphistegina gibbosa & & & & & & & & & 14,9 & 19,34 \\
\hline Amphistegina lessonii & & & & & & & & & 17,1 & 14,40 \\
\hline Archaias angulatus & & & & & 9,2 & 9,54 & & & & \\
\hline Articulina atlantica & & & & & 4,9 & 6,19 & & & & \\
\hline Elphidium discoidale & & & 3,6 & 4,67 & & & & & & \\
\hline Hanzawaia bertheloti & & & 3,1 & 5,00 & & & & & & \\
\hline Hanzawaia concentrica & & & 3,9 & 6,11 & & & & & & \\
\hline Massilina pernambucensis & & & & & 3,4 & 5,57 & & & & \\
\hline Peneroplis bradyi & & & & & & & 16,0 & 11,62 & & \\
\hline Peneroplis carinatus & 41,1 & 41,28 & & & & & & & & \\
\hline Peneroplis proteus & & & & & 4,9 & 6,19 & & & & \\
\hline Quinqueloculina bicarinata & & & 6,4 & 3,60 & & & & & & \\
\hline Quinqueloculina bicostata & & & & & 2,6 & 4,79 & & & & \\
\hline Quinqueloculina disparilis curta & & & & & 7,4 & 5,78 & & & & \\
\hline Quinqueloculina microcostata & & & & & 4,5 & 4,86 & & & & \\
\hline Textularia agglutinans & & & & & 3,1 & 6,12 & & & & \\
\hline Textularia candeiana & & & & & 8,3 & 7,46 & & & & \\
\hline Textularia gramen & & & & & 9,3 & 5,71 & & & & \\
\hline
\end{tabular}


Tabela 6. Número de indivíduos das espécies da plataforma externa.

\begin{tabular}{|c|c|c|c|c|c|c|c|c|c|c|c|c|}
\hline Espécies / Amostras & 128 & 137 & 139 & 140 & 142 & 145 & 150 & 152 & 158 & 159 & 167 & Total \\
\hline Amphistegina gibbosa & 15 & 8 & 39 & 50 & 51 & 27 & 39 & 0 & 7 & 22 & 22 & 280 \\
\hline Amphistegina lessonii & 23 & 36 & 9 & 45 & 43 & 23 & 87 & 1 & 31 & 49 & 28 & 375 \\
\hline Archaias angulatus & 9 & 6 & 16 & 5 & 11 & 5 & 3 & 4 & 3 & 2 & 7 & 71 \\
\hline Bigenerina nodosaria & 10 & 5 & 3 & 2 & 6 & 5 & 1 & 16 & 0 & 0 & 1 & 49 \\
\hline Discorbis mira & 2 & 2 & 7 & 9 & 0 & 4 & 15 & 0 & 27 & 19 & 7 & 92 \\
\hline Elphidium discoidale & 5 & 7 & 2 & 0 & 0 & 0 & 2 & 17 & 3 & 3 & 10 & 49 \\
\hline Globigerinoides ruber & 5 & 6 & 2 & 8 & 5 & 8 & 10 & 16 & 20 & 10 & 6 & 96 \\
\hline Hanzawaia concentrica & 9 & 1 & 0 & 0 & 0 & 1 & 2 & 16 & 0 & 0 & 3 & 32 \\
\hline Peneroplis bradyi & 43 & 15 & 6 & 11 & 13 & 19 & 5 & 10 & 1 & 6 & 18 & 147 \\
\hline Peneroplis carinatus & 8 & 35 & 46 & 31 & 48 & 25 & 4 & 22 & 20 & 22 & 23 & 284 \\
\hline Quinqueloculina bicarinata & 5 & 18 & 15 & 10 & 11 & 14 & 3 & 6 & 7 & 10 & 5 & 104 \\
\hline Quinqueloculina parkeri & 0 & 1 & 4 & 11 & 0 & 0 & 0 & 0 & 16 & 11 & 1 & 44 \\
\hline Textularia gramen & 14 & 15 & 13 & 6 & 9 & 4 & 6 & 5 & 6 & 4 & 16 & 98 \\
\hline
\end{tabular}

Tabela 7. Medidas descritivas dos agrupamentos de espécies encontrados na plataforma externa pelo método de Ward. FA= frequência absoluta.

\begin{tabular}{|c|c|c|c|c|c|c|c|c|c|c|c|c|}
\hline \multirow[t]{2}{*}{ Variáveis (FA) } & \multicolumn{2}{|l|}{ Grupo A } & \multicolumn{2}{|l|}{ Grupo B } & \multicolumn{2}{|l|}{ Grupo C } & \multicolumn{2}{|l|}{ Grupo D } & \multirow{2}{*}{$\begin{array}{c}\text { Grupo E } \\
\text { Média }\end{array}$} & \multicolumn{3}{|c|}{ Grupo F } \\
\hline & Média & $\begin{array}{l}\text { Desvio } \\
\text { Padrão }\end{array}$ & Média & $\begin{array}{l}\text { Desvio } \\
\text { Padrão }\end{array}$ & Média & $\begin{array}{l}\text { Desvio } \\
\text { Padrão }\end{array}$ & Média & $\begin{array}{l}\text { Desvio } \\
\text { Padrão }\end{array}$ & & $\begin{array}{l}\text { Desvio } \\
\text { Padrão }\end{array}$ & Média & $\begin{array}{l}\text { Desvio } \\
\text { Padrão }\end{array}$ \\
\hline Amphistegina gibbosa & & & & & & & & & 25,5 & 17,47 & & \\
\hline Amphistegina lessonii & & & & & & & 34,1 & 22,89 & & & & \\
\hline Archaias angulatus & & & & & 6,5 & 4,16 & & & & & & \\
\hline Bigenerina nodosaria & & & & & 5,4 & 4,88 & & & & & & \\
\hline Discorbis mira & & & 9,2 & 8,64 & & & & & & & & \\
\hline Elphidium discoidale & & & & & 6,1 & 5,19 & & & & & & \\
\hline Globigerinoides ruber & & & & & 8,7 & 5,22 & & & & & & \\
\hline Hanzawaia concentrica & & & & & 5,3 & 6,02 & & & & & & \\
\hline Peneroplis bradyi & 13,4 & 11,32 & & & & & & & & & & \\
\hline Peneroplis carinatus & & & & & & & & & & & 25,8 & 13,70 \\
\hline $\begin{array}{l}\text { Quinqueloculina } \\
\text { bicarinata }\end{array}$ & & & & & 9,5 & 4,76 & & & & & & \\
\hline Quinqueloculina parkeri & & & 4,9 & 6,13 & & & & & & & & \\
\hline Textularia gramen & & & & & 8,9 & 4,68 & & & & & & \\
\hline
\end{tabular}

No Grupo A encontrou-se individualizada a espécie Amphistegina lessonii, com elevada abundância na amostra 146 (112 espécimes), e baixa abundância na amostra 131 (4 espécimes). Esta espécie foi a mais frequente do talude (275 indivíduos), apresentando, em média, 45,8 indivíduos neste grupo. No Grupo B reuniram-se as espécies Amphistegina gibbosa (28 indivíduos), Cassidulina curvata (33 indivíduos) e Siphonina reticulata (47 indivíduos). A média de indivíduos neste grupo variou de 4,7 a 7,8. No Grupo C foram encontradas as espécies Sigmavirgulina tortuosa, Angulogerina angulosa occidentalis e Cassidulina subglobosa, com abundância absoluta 61, 69 e 71 espécimes, respectivamente. A média de indivíduos neste grupo variou de 10,2 a 11,8 . No Grupo D ficaram reunidas as espécies mais frequentes do talude após Ampphistegina lessonii, sendo elas: Cassidulina laevigata (97 espécimes), Cibicides pseudoungerianus (108 espécimes) e Globigerinoide ruber (127 espécimes). A média de indivíduos neste grupo variou de 16,2 a 21,2. (Tab. 8 e 9).
Para aplicação do método k-Médias utilizaram-se como sementes iniciais os quatro grupos formados pelo método de Ward e ficou evidenciado que as 10 espécies do talude foram classificadas nos mesmos agrupamentos pelos dois métodos. 0 coeficiente $R^{2}$ obtido correspondeu a $80 \%$, indicando que os grupos encontrados são homogêneos internamente.

0 dendrograma apresentado na figura 6 corresponde à análise de agrupamento entre as 38 amostras (modo Q), segundo os teores sedimentológicos, representados pelas cinco variáveis (teores de carbonato, siliciclasto, areia, cascalho e lama) presentes em cada amostra.

O valor do índice de correlação cofenética obtido para essa associação de amostras correspondeu a 0,7. No dendrograma foi realizado um corte na distância 24, onde observou-se cinco grupos A, B, C, D e E assim definidos: o Grupo A foi formado por cinco amostras, constituídas por altas taxas de areia (em média 96,1\%) e siliciclasto (em média 65,5\%) e baixos teores de cas- 
calho (em média 3,2\%), carbonato (em média 34,5\%) e lama (em média 0,8\%). No Grupo B reuniram-se doze amostras com alto teor de areia (em média 81,5\%), carbonato (em média 58,2\%) e cascalho (em média15\%), e baixas taxas de siliciclasto (em média 41,8\%) e lama (em média 3,6\%).

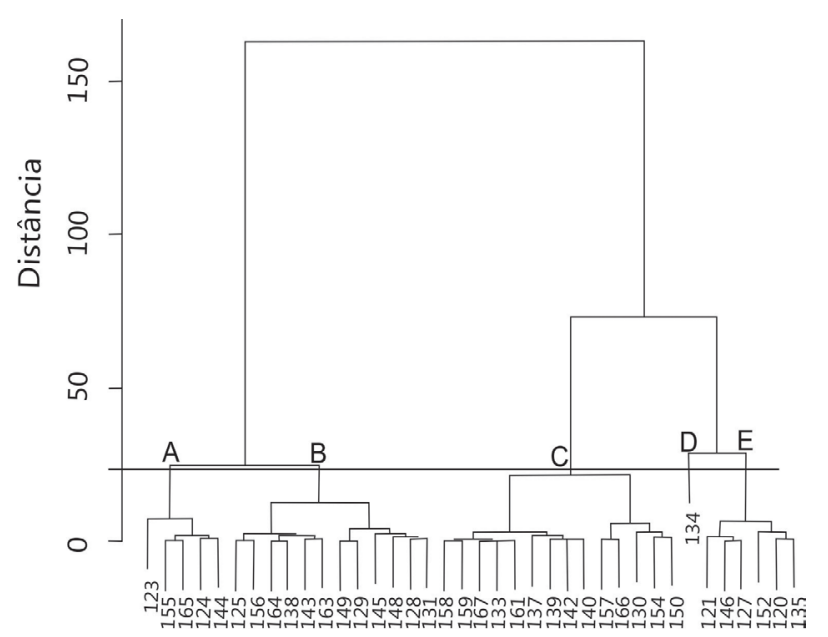

Amostras

Figura 6. Dendrograma do Método de Ward com base na distância euclidiana quadrática agrupando as amostras considerando as variáveis sedimentológicas (Carbonato, Siliciclástico e Granulometria).

Tabela 8. Número de indivíduos das espécies do talude.

\begin{tabular}{lccccccc}
\hline Espécies / Amostras & $\mathbf{1 2 1}$ & $\mathbf{1 2 7}$ & $\mathbf{1 3 1}$ & $\mathbf{1 3 5}$ & $\mathbf{1 4 6}$ & $\mathbf{1 6 6}$ & Total \\
\hline Amphistegina gibbosa & 0 & 1 & 0 & 1 & 4 & 22 & 28 \\
Amphistegina lessonii & 44 & 25 & 4 & 5 & 112 & 85 & 275 \\
Angulogerina angulosa occidentalis & 1 & 26 & 34 & 0 & 7 & 1 & 69 \\
Cassidulina curvata & 0 & 0 & 1 & 25 & 1 & 6 & 33 \\
Cassidulina laevigata & 17 & 38 & 1 & 15 & 16 & 10 & 97 \\
Cassidulina subglobosa & 5 & 7 & 43 & 9 & 7 & 0 & 71 \\
Cibicides peseudoungerianus & 46 & 20 & 12 & 10 & 15 & 5 & 108 \\
Globigerinoides ruber & 20 & 20 & 17 & 46 & 16 & 8 & 127 \\
Sigmavirgulina tortuosa & 5 & 26 & 17 & 2 & 10 & 1 & 61 \\
Siphonina reticulata & 2 & 3 & 4 & 5 & 6 & 27 & 47 \\
\hline
\end{tabular}

Tabela 9. Medidas descritivas dos agrupamentos de espécies encontrados no talude pelo método de Ward. FA= frequência absoluta.

\begin{tabular}{|c|c|c|c|c|c|c|c|c|}
\hline \multirow[t]{2}{*}{ Variáveis (FA) } & \multicolumn{2}{|l|}{ Grupo A } & \multicolumn{2}{|l|}{ Grupo B } & \multicolumn{2}{|l|}{ Grupo C } & \multicolumn{2}{|l|}{ Grupo D } \\
\hline & Média & $\begin{array}{l}\text { Desvio } \\
\text { Padrão }\end{array}$ & Média & $\begin{array}{l}\text { Desvio } \\
\text { Padrão }\end{array}$ & Média & $\begin{array}{l}\text { Desvio } \\
\text { Padrão }\end{array}$ & Média & $\begin{array}{l}\text { Desvio } \\
\text { Padrão }\end{array}$ \\
\hline Amphistegina gibbosa & & & 4,7 & 8,62 & & & & \\
\hline Amphistegina lessonii & 45,8 & 44,20 & & & & & & \\
\hline Angulogerina angulosa occidentalis & & & & & 11,5 & 14,76 & & \\
\hline Cassidulina curvata & & & 5,5 & 9,81 & & & & \\
\hline Cassidulina laevigata & & & & & & & 16,2 & 12,22 \\
\hline Cassidulina subglobosa & & & & & 11,8 & 15,57 & & \\
\hline Cibicides peseudoungerianus & & & & & & & 18,0 & 14,60 \\
\hline Globigerinoides ruber & & & & & & & 21,2 & 12,94 \\
\hline Sigmavirgulina tortuosa & & & & & 10,2 & 9,75 & & \\
\hline Siphonina reticulata & & & 7,8 & 9,50 & & & & \\
\hline
\end{tabular}


O grupo D foi similar aos grupos C e E em relação ao teor de carbonato, mas diferiu desses grupos, principalmente, pelo alto teor de lama e baixo teor de areia. Dessa forma o grupo D caracterizou-se pela presença de lama carbonática arenosa (Tab. 10).

0 método k-Médias foi aplicado utilizando-se como sementes iniciais os cinco grupos formados pelo método de Ward. 0 coeficiente $R^{2}$ obtido foi $80 \%$ indicando que os grupos encontrados são homogêneos internamente. Entretanto, verificou-se que das 38 amostras, 35 (92\%) foram classificadas nos mesmos agrupamentos pelos dois métodos. As amostras 125, 156 e 163 pertencentes ao grupo B pelo método de Ward deslocaram-se para ao Grupo A, pelo método k-Médias. Estas amostras apresentaram índices elevados de siliciclasto, principal característica do Grupo A. Portanto, analisando as medidas descritivas verificou-se que o método k-Médias representou melhor o agrupamento A (Tab. 11e 12). As fotomicrografias das espécies selecionadas estão expostas nas figuras 7 e 8 .

Tabela 10. Valores percentuais de carbonato, siliciclasto, cascalho, areia e lama dos sedimentos em cada amostra.

\begin{tabular}{cccccc}
\hline AMOSTRAS & CARBONATO SILICICLASTO & CASCALHO & AREIA & LAMA \\
\hline 123 & 6,3 & 93,7 & 0,5 & 99 & 0,5 \\
124 & 30,7 & 69,3 & 0,6 & 98,7 & 0,7 \\
125 & 37,3 & 62,7 & 20 & 78,6 & 1,4 \\
156 & 40,3 & 59,7 & 23,6 & 76,4 & 0 \\
164 & 53 & 47 & 14,9 & 84,8 & 0,3 \\
155 & 50,3 & 49,7 & 7 & 92,4 & 0,6 \\
143 & 54,7 & 45,3 & 18,7 & 73,4 & 7,9 \\
154 & 83 & 17 & 35,3 & 56 & 8,7 \\
138 & 56,3 & 43,7 & 17,5 & 82 & 0,5 \\
144 & 38 & 62 & 4,4 & 95 & 0,6 \\
133 & 93 & 7 & 32,8 & 66,5 & 0,7 \\
161 & 90,7 & 9,3 & 30,5 & 68,4 & 1 \\
163 & 43,7 & 56,3 & 16,6 & 75,3 & 8,1 \\
148 & 63 & 37 & 6,1 & 93,3 & 0,7 \\
149 & 74,7 & 25,3 & 21,8 & 76,9 & 1,3 \\
165 & 47 & 53 & 3,3 & 95,3 & 1,4 \\
130 & 70,7 & 29,3 & 38 & 42,1 & 19,9 \\
120 & 72,7 & 27,3 & 3,4 & 72,5 & 24,1 \\
129 & 69 & 31 & 18,8 & 76,9 & 4,4 \\
157 & 93 & 7 & 52,1 & 45,9 & 2 \\
134 & 81 & 19 & 3,8 & 28,2 & 67,9 \\
142 & 98,3 & 1,7 & 27,8 & 62,7 & 9,5 \\
139 & 88,7 & 11,3 & 22,6 & 66,5 & 10,9 \\
145 & 82 & 18 & 3,7 & 92,9 & 3,4 \\
158 & 97,7 & 2,3 & 34,6 & 64,7 & 0,7 \\
159 & 96,3 & 3,7 & 33 & 66 & 1 \\
140 & 100 & 0 & 22,1 & 67,7 & 10,2 \\
167 & 89,3 & 10,7 & 27,1 & 70,3 & 2,6 \\
137 & 92 & 8 & 19 & 78,2 & 2,8 \\
152 & 67,3 & 32,7 & 18,3 & 60,7 & 21 \\
150 & 92,3 & 7,7 & 43,9 & 47,9 & 8,1 \\
128 & 63 & 37 & 12 & 82,9 & 5 \\
166 & 100 & 0 & 55 & 38,4 & 6,6 \\
146 & 94,7 & 5,3 & 4,9 & 72,5 & 22,6 \\
131 & 61,3 & 38,7 & 6 & 84,1 & 9,9 \\
127 & 93,3 & 6,7 & 2,9 & 76,3 & 20,8 \\
121 & 87,7 & 12,3 & 4,5 & 66,7 & 28,8 \\
135 & 68,7 & 31,3 & 0 & 68,4 & 31,6 \\
\hline & & & & &
\end{tabular}



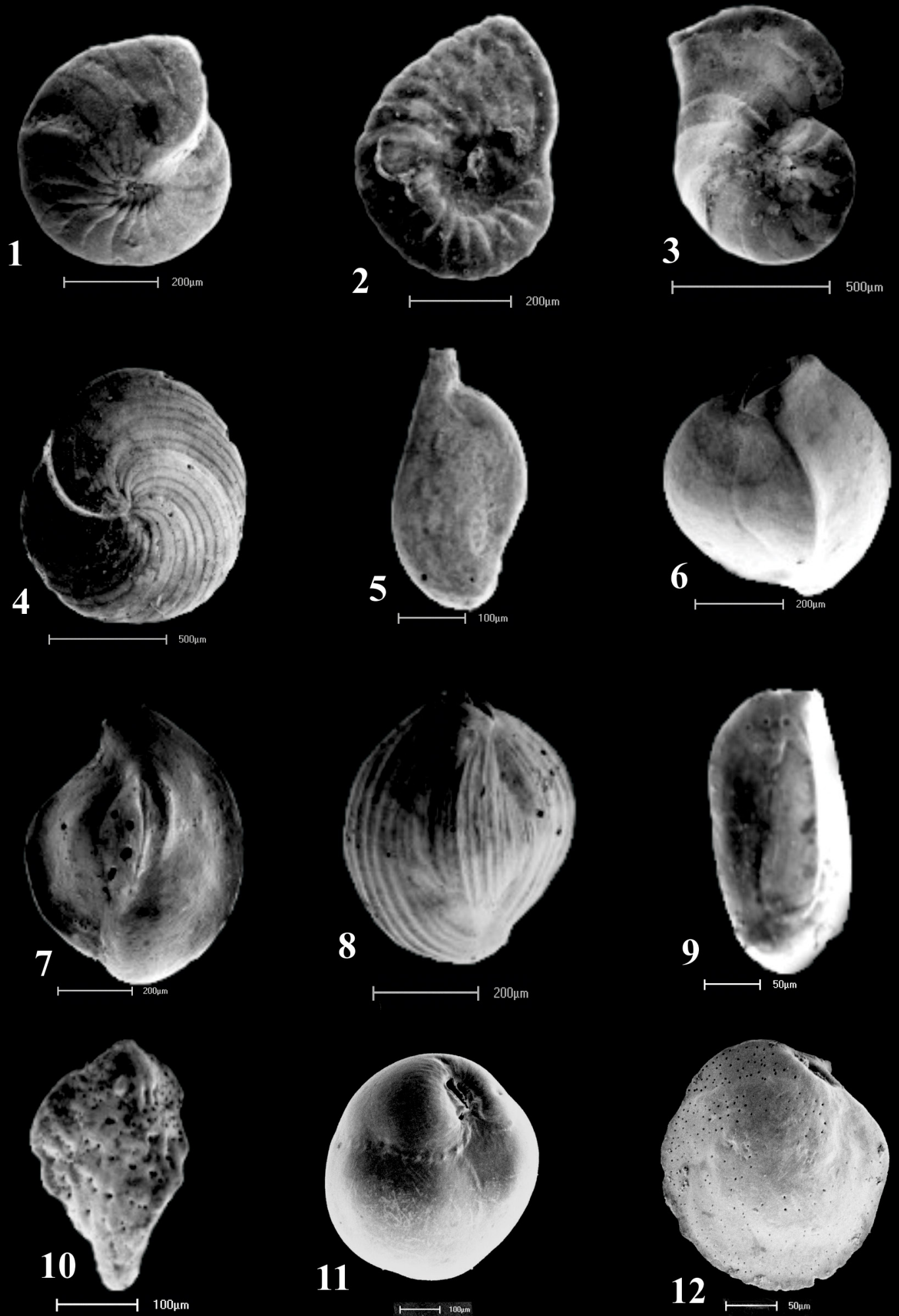

Figura 7. Fotomicrografias de espécies selecionadas. 1. Peneroplis carinatus. 2. P. bradyi. 3. P. proteus. 4. Archaias angulatus. 5. Massilina pernambucensis. 6. Quinqueloculina bicarinata. 7. Q. bicostata. 8. Q. microcostata. 9. Q. moynensis. 10. Sigmavirgulina tortuosa. 11. Cassidulina subglobosa. 12. C. curvata. 

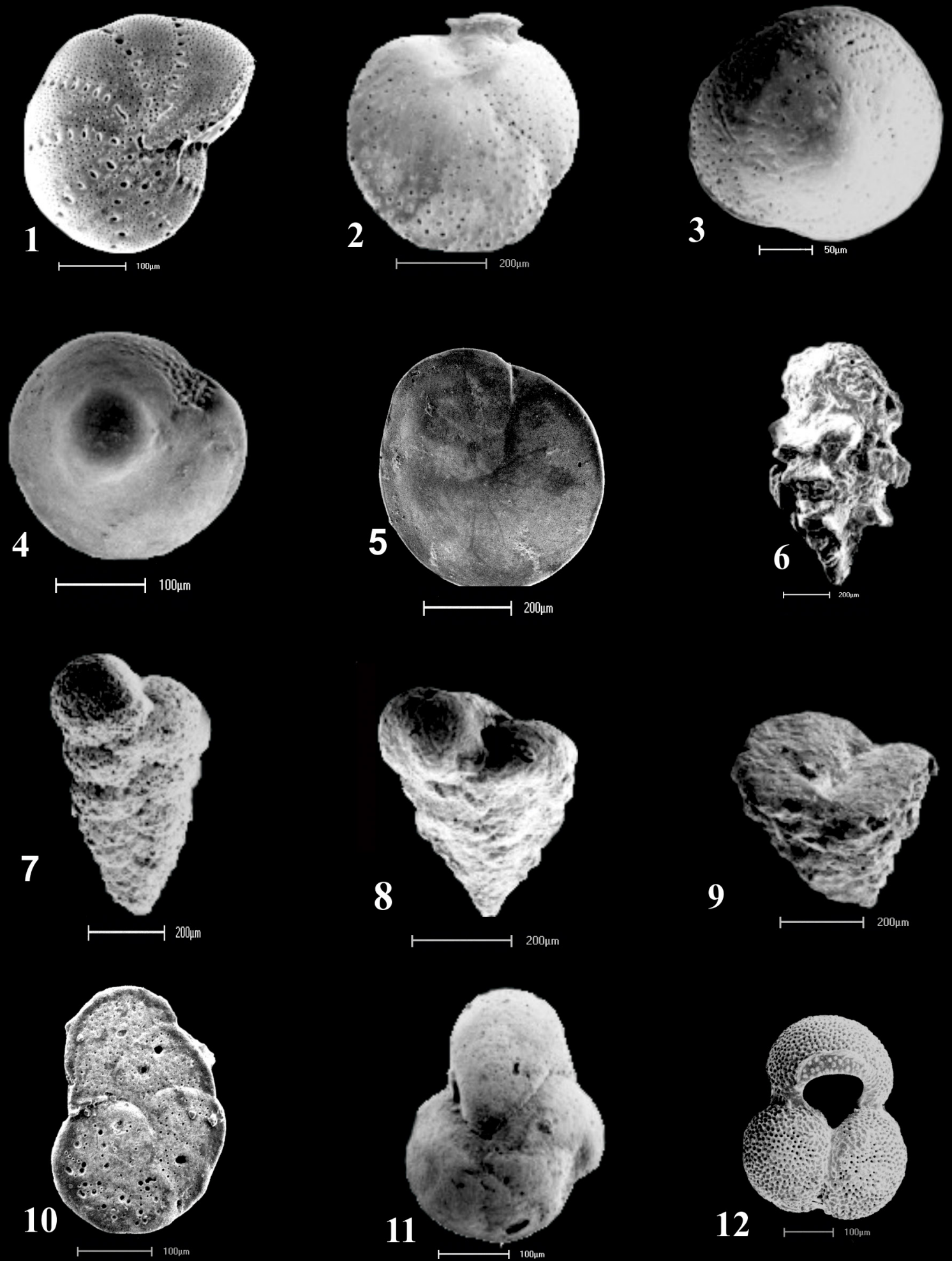

Figura 8. Fotomicrografias de espécies selecionadas. 1. Elphidium discoidale. 2. Siphonina reticulata. 3. Dicorbis mira. 4. Amphistegina gibbosa. 5. A. lessonii. 6. Bigenerina nodosaria. 7. Textularia agglutinans. 8. T. candeiana. 9. T. gramen. 10. Cibicides pseudoungerianus, (lado dorsal). 11. C. pseudoungerianus, (lado ventral). 12. Globigerinoides ruber. 
Tabela 11. Medidas descritivas dos agrupamentos de amostras formados pelo método de Ward.

\begin{tabular}{lcccccccccc}
\hline & Grupo A & \multicolumn{3}{c}{ Grupo B } & \multicolumn{3}{c}{ Grupo C } & \multicolumn{2}{c}{ Grupo D } & \multicolumn{2}{c}{ Grupo E } \\
\cline { 2 - 10 } \begin{tabular}{l} 
Variáveis \\
\multicolumn{1}{c}{$\%)$}
\end{tabular} & Média & $\begin{array}{l}\text { Desvio } \\
\text { Padrão }\end{array}$ & Média & $\begin{array}{c}\text { Desvio } \\
\text { Padrão }\end{array}$ & Média & $\begin{array}{c}\text { Desvio } \\
\text { Padrão }\end{array}$ & Média & $\begin{array}{c}\text { Desvio } \\
\text { Padrão }\end{array}$ & Média & $\begin{array}{c}\text { Desvio } \\
\text { Padrão }\end{array}$ \\
\hline Carbonato & 34,5 & 17,52 & 58,2 & 13,56 & 91,8 & 7,72 & 81,0 & 80,7 & 34,27 \\
Siliciclasto & 65,5 & 17,52 & 41,8 & 13,55 & 8,2 & 7,72 & 19,0 & 19,3 & 11,89 \\
Cascalho & 3,2 & 2,74 & 15,0 & 6,60 & 33,8 & 10,68 & 3,8 & 5,6 & 33,85 \\
Areia & 96,1 & 2,77 & 81,5 & 6,53 & 60,1 & 11,98 & 28,2 & 69,5 & 23,82 \\
Lama & 0,8 & 0,37 & 3,6 & 3,48 & 6,1 & 5,57 & 67,9 & & 24,8 & 4,43 \\
\hline
\end{tabular}

Tabela 12. Medidas descritivas dos agrupamentos de amostras formados pelo método k-Médias.

\begin{tabular}{lcccccccccc}
\hline \multirow{2}{*}{\begin{tabular}{c} 
Variáveis \\
\multicolumn{1}{c}{$\%)$}
\end{tabular}} & Grupo A & \multicolumn{3}{c}{ Grupo B } & \multicolumn{3}{c}{ Grupo C } & \multicolumn{2}{c}{ Grupo D } & \multicolumn{2}{c}{ Grupo E } \\
\cline { 2 - 10 } & Média & $\begin{array}{c}\text { Desvio } \\
\text { Padrão }\end{array}$ & Média & $\begin{array}{c}\text { Desvio } \\
\text { Padrão }\end{array}$ & Média & $\begin{array}{c}\text { Desvio } \\
\text { Padrão }\end{array}$ & Média & $\begin{array}{c}\text { Desvio } \\
\text { Padrão }\end{array}$ & Média & $\begin{array}{c}\text { Desvio } \\
\text { Padrão }\end{array}$ \\
\cline { 2 - 11 } Carbonato & 36,7 & 13,71 & 64,1 & 9,61 & 91,8 & 7,72 & 81,0 & 80,7 & 34,27 \\
Siliciclasto & 63,3 & 13,71 & 35,8 & 9,56 & 8,2 & 7,72 & 19,0 & 19,3 & 11,89 \\
Cascalho & 9,5 & 9,18 & 13,3 & 6,62 & 33,8 & 10,68 & 3,8 & 5,6 & 33,85 \\
Areia & 88,8 & 10,25 & 83,0 & 6,86 & 60,1 & 11,98 & 28,2 & 69,5 & 23,82 \\
Lama & 1,7 & 2,64 & 3,7 & 3,44 & 6,1 & 5,57 & 67,9 & & 24,8 & 4,43 \\
\hline
\end{tabular}

\section{Discussão dos resultados}

A maior abundância de Peneroplis carinatus em plataforma interna, motivo pelo qual essa espécie se mostrou em um grupo a parte no dendograma (Grupo A - Figura 2), também foi observada por Figueiredo et al. (2011), em estudo de análise do zoneamento batimétrico das assembleias de foraminíferos da plataforma e do talude continentais do município de Conde (BA).

A associação observada entre as espécies Peneroplis proteus e Archaias angulatus nos grupos B e C na plataforma interna, assemelha-se à registrada por Bruno (2008), em batimetria entre 25-35 m na plataforma continental de Ilhéus, na Bahia. Li et al. (1998) também exibiram Archaias angulatus como principal espécie em batimetria entre 12-40 m, além das espécies Astigerina carinata, Quinqueloculina agglutinans e Valvulina oviedoiana, na Baía aberta de Frank Sound - Grand Cayman próximo de Cuba. Segundo Murray (2006), a espécie Archaias angulatus é confinada no oceano Atlântico, principalmente Caribeano, em profundidades até $20 \mathrm{~m}$. Araújo \& Araújo (2010) observaram que a abundância de Archaias angulatus e Peneroplis proteus decresce no sentido da plataforma interna para a externa no litoral norte do Estado da Bahia.

Os gêneros Archaias e Peneroplis são denominados de "macroforaminíferos", sendo característicos de ambientes de zona fótica com sedimentação carbonática. Segundo Hohenegger et al. (1999), foraminíferos com maiores dimensões, a exemplo dos gêneros Archaias e Peneroplis, representam componentes de significati- va importância nas comunidades de mares tropicais e subtropicais, sendo predominantemente encontrados desde a zona intermarés até o limite da zona eufótica.

Na plataforma média as espécies Amphistegina lessonii, A. gibbosa, Archaias angulatus, Homotrema rubrum e Heterostegina suborbivularis, dentre outras, foram também encontradas por Andrade (1997) na margem costeira até $45 \mathrm{~m}$ de profundidade, no litoral norte do Estado da Bahia entre Itapuã e Praia do Forte.

Bruno (2008) encontrou as espécies Amphistegina lessonii, Amphistegina gibbosa, Archaias angulatus, Discorbis mira, Peneroplis pertusus, Peneroplis proteus, Peneroplis carinatus e Cibicides aknerianus em locais cuja batimetria estava entre $40-50 \mathrm{~m}$ na plataforma de Ilhéus na Bahia. Neste trabalho foi registrada associação semelhante na plataforma externa. Figueiredo et al. (2011) também constataram expressiva abundância de Amphistegina lessonii e A. gibbosa, Archaias angulatus em plataforma média a externa do município de Conde (BA), reforçando a significativa presença destas espécies em plataformas de águas quentes e carbonáticas.

No talude os subgrupos foram formados considerando a abundância das espécies. A maior representatividade da espécie Amphistegina lessonii neste intervalo batimétrico reflete o transporte por fluxo de massa e/ou correntes de turbidez de sedimento transportado da plataforma continental. Leipnitz \& Leipnitz (1996) relataram as formas vivas dessa espécie em batimetria máxima de 129 m, porque são epifaunais, epífitas, herbívoras e possuem simbiontes. Amphistegina lessonii é encontrada nas praias de Salvador, sendo comum em 
plataformas e áreas recifais do litoral norte da Bahia (Andrade, 1997; Machado et al., 2006; Araújo \& Araújo, 2010). Araújo \& Machado (2008b) assinalaram que a maior abundância dessa espécie encontra-se no talude, em frente a recifes da praia de Guarajuba, no litoral norte da Bahia. Em Porto Rico, ela foi relatada como uma das espécies mais abundantes entre as assembleias recifais (Seiglie, 1968). Amphistegina lessonii ocorre também, no Indo-Pacífico e Mediterrâneo do sul, alcançando até $90 \mathrm{~m}$ de profundidade (Murray, 2006) e no Hawaii é abundante em áreas com menos de $10 \mathrm{~m}$ de profundidade (Hallock, 1984). 0 gênero Cassidulina tem sido registrado em uma ampla variedade de ambientes, de nerítico a batial (Miao \& Thunell, 1993), e frequentemente responde à entrada de nutrientes no meio ambiente (Nees, 1998). Cassidulina laevigata é epifaunal, típica de plataformas banhadas por águas quentes do Atlântico (Mackensen \& Hald, 1988), enquanto Cassidulina subglobosa apresenta-se geralmente em diversas batimetrias (Miao \& Thunell, 1993). 0 gênero Cibicides ocorre geralmente em substrato duro, águas frias a quentes, em ambiente de plataforma até batial, a 2000 m de profundidade (Murray, 1991, 2006; Culver, 1988). Segundo Araújo \& Araújo (2010), a abundância de Amphistegina lessonii e A. gibbosa, nesta área estudada, aumenta no sentido da plataforma interna para externa.

Os resultados observados a partir do agrupamento das 38 amostras segundo as variáveis sedimentológicas (carbonato, siliciclasto, areia, cascalho e lama) evidenciam as relações entre o tipo de sedimento com a batimetria e consequentemente com as espécies abundantes em cada subambiente (plataformas interna, média e externa, e talude). Essa relação está associada à efetiva contribuição dos diferentes organismos na produção de bioclastos, nos distintos intervalos de profundidade. De acordo com Dias (2000), na plataforma continental brasileira observa-se uma grande variação nos tipos de bioclastos tanto regionalmente quanto em função da profundidade.

Considerando os dados obtidos neste trabalho, o grupo C (Fig. 6) foi caracterizado pela presença de areia carbonática cascalhosa e suas amostras estão localizadas, predominantemente, nas plataformas média e externa e talude. Bruno (2008) registrou sedimento constituído de areia e cascalho carbonático em batimetria entre 40-50 m, na plataforma de Ilhéus, na Bahia.

Andrade (1997), em estudo envolvendo foraminíferos na zona de transição carbonato-siliciclasto entre Itapuã e Praia do Forte, no litoral norte da Bahia, encontrou nas amostras silicicláticas de areia fina e lamosa as formas: Ammonia beccarii, Nonionella atlântica, Hanzawaia concentrica, Elphidium poeyanum, Bolivina compta, Discorbis mira, D. floridanus e Cibicides aknerianus. Nas regiões carbonáticas, onde ocorrem recifes de coral (Praia do Forte) foram observadas as espécies: Amphistegina lessonii, A. gibbosa, Archaias augulatus, Homotrema rubrum, Heterostegina suborbicularis, den- tre outras. Macedo \& Machado (1995) assinalaram as espécies Amphistegina lessonii e Archaias augulatus como formas dominantes associadas ao substrato arenoso. Li et al. (1998) registraram a espécie Archaias angulatus em sedimento siliciclastos e Amphistegina gibbosa em sedimento carbonático na Baía de Frank Sound - Cayman, próximo de Cuba. Renema (2006), na plataforma leste da Indonésia, no arquipélago de Supermonde, que consiste de sedimento carbonático-recifal identificou Amphistegina papillosa, A. radiata, Operculina ammonoides e Parasorites orbitolitoides. As espécies Peneroplis pertusus, Peneroplis proteus e Archaias angulatus são citadas como formas representantes do ambiente carbonático por Bruno (2008) e Machado et al. (2006), na Bahia, e por Batista et al. (2007) no ambiente recifal dos Parrachos de Maracajaú, Rio Grande do Norte.

\section{Conclusões}

A utilização conjunta dos dois métodos no agrupamento das espécies (modo R) e das amostras (modo Q) permitiu determinar através do método de Ward o número de grupos adequados a serem utilizados na análise dos dados. 0 método k-Médias otimizou estes resultados ao classificar as espécies e as amostras nos grupos formados, demonstrando a homogeneidade dentro dos grupos e heterogeneidade entre grupos.

Os resultados obtidos evidenciaram que a plataforma interna do litoral norte da Bahia apresenta sedimento constituído de areia siliciclástica e as espécies de foraminíferos predominantes são: Peneroplis carinatus, Archaias angulatus e Peneroplis proteus. Além dessas espécies formam a assembléia dessa plataforma as seguintes espécies: Textularia agglutinans, Massilina pernambucensis, Quinqueloculina moynensis, Q. microcostata, Textularia gramen, Peneroplis bradyi e Textularia candeiana.

A plataforma média é caracterizada por sedimento composto de areia siliciclástica e carbonática apresentando principalmente as espécies: Amphistegina lessonii, A. gibbosa e Peneroplis carinatus. Também compõem a assembleia dessa plataforma as espécies: Quinqueloculina bicarinata, Hanzawaia concentrica, Elphidium discoidale, Hanzawaia bertheloti, Massilina pernambucensis, Q. microcostata, Textularia agglutinans, Q.bicostata, Articulina atlântica, Peneroplis proteus, Q. disparilis curta, Textularia candeiana, T. gramen e Peneroplis bradyi. A plataforma média é a área de transição da sedimentação de areia siliciclástica da plataforma interna e areia carbonática da plataforma externa e do talude.

Na plataforma externa o sedimento é formado por areia carbonática cascalhosa e as espécies de foraminíferos predominantes são: Amphistegina lessonii, A. gibbosa, Peneroplis carinatus, Globigerinoides ruber e Discorbis mira. Também fazem parte da assembléia dessa plataforma as espécies: Peneroplis bradyi, Elphidium 
discoidale, Bigenerina nodosaria, Hanzawaia concentrica, Quinqueloculina bicarinata, Textularia gramen e $Q$. parkeri.

No talude observa-se sedimento formado por areia carbonática lamosa tendo as seguintes espécies predominando: Amphistegina lessonii, Cassidulina laevigata, Cibicides pseudoungerianus e Globigerinoide ruber. A assembleia de foraminíferos presentes no talude é composta também por: Cassidulina curvata, Siphonina reticulata, C. subglobosa, Angulogerina angulosa angulosa, Sigmavirgulina tortuosa, C. laevigata e Cibicides peseudoungerianus.

\section{Referências}

Ab'Saber, A.N., Tundisi, J.G., Forneris, L., Marino, M.C. \& Rocha, O., Tundisi, T., Schaeffer-Novelli, Y., Vouno, Y.S. \& Watanabe, S. 1997. Glossário de ecologia. 2ª ed., Editora Aciesp, São Paulo, SP, Brasil, 352p.

Andrade, E. J. 1997. Distribuição dos Foraminíferos Recentes na Transição Carbonatos / Siliciclástos na Região de Praia do Forte, Litoral Norte do Estado da Bahia, 111p. Dissertação de Mestrado, Programa de Pós-graduação em Geologia, Instituto de Geociências, Universidade Federal da Bahia.

Araújo, H.A.B. 2009. Assembléias de foraminíferos indicadores de mudanças ambientais no complexo recifal de Abrolhos, Bahia, 209p.Tese de Doutorado, Programa de Pós-graduação em Geologia, Instituto de Geociências, Universidade Federal da Bahia.

Araújo, T.M.F. \& Araújo H.A.B. 2010. Assembléias de foraminíferos encontradas nos sedimentos superficiais da plataforma continental e talude superior do norte da Bahia. Revista de Geologia, 23 (1): 115-134.

Araújo, T.M.F. \& Machado, A.J.M. 2008a. Eventos bioestratigráficos, paleoclimáticos e paleobatimétricos do talude continental superior da Bahia, evidenciados através do estudo da fauna dos Foraminíferos. Gravel, 6 (1): 27-45.

Araújo, T.M.F. \& Machado, A.J.M. 2008b. Foraminíferos da subsuperfície do talude continental superior do norte da Bahia, Brasil. Revista de Geologia, 21(1): 49-77.

Araújo, T.M.F. \& Machado, A.J.M. 2008c. Análise sedimentar e micropaleontológica (Foraminíferos) de Seções Quaternárias do Talude Continental Superior do Norte da Bahia, Brasil. Pesquisas em Geociências, 35(2): 97-113.

Araújo, T.M.F. 2004. Estudo da microfauna de foraminíferos do sedimento da superfície e da subsuperfície da plataforma e do talude continentais da região norte do Estado da Bahia (Salvador à Barra do Itariri), 528p. Tese de Doutorado, Programa de Pós-graduação em Geologia, Instituto de Geociências, Universidade Federal da Bahia.

Asmus, H.E. 1984. Geologia da margem continental brasileira. In: Schobbenhaus, C., Campos, D. A., Derzei, G.R., Asmus, H.E. (eds), Geologia do Brasil-Texto explicativo do mapa geológico do Brasil e da área adjacente incluindo depósitos minerais, escala 1:500.000. Departamento Nacional de Produção Mineral, 501p.

Batista, D.S., Vilela, C.G. \& Koutsoukos, E.A.M. 2007. Influência dos Fatores Ambientais na Preservação da Microfauna de Foraminíferos Bentônicos no Ambiente Recifal dos Parrachos de Maracajaú, RN, Brasil. Anuário do Instituto de Geociências, 30: 92-103.
Bergue C.T. \& Coimbra J.C. 2008. Abordagens faunísticas e geoquímicas em microfósseis calcários e suas aplicações à paleoceanografia e paleoclimatologia. Boletim do Museu Paraense Emílio Goeldi, Ciências Naturais, 3(2): 115-126.

Bruno, R.L.M. 2008. Avaliação das assembleias de foraminíferos na Plataforma de transição carbonato-siliciclasto, região de Ilhéus, Bahia, 121p. Dissertação de Mestrado, Programa de Pós-graduação em Geologia, Instituto de Geociências, Universidade Federal da Bahia.

Bussab, W.O., Miazaki, É.S. \& Andrade, D.F. 1990. Introdução à análise de agrupamentos, São Paulo, ABE, 105p.

Clarke, K.R. \& Warwick, R.M. 1994. Change in Marine Communities: An Approach to Statistical Analysis and Interpretation. Plymouth: Plymouth Marine Laboratory, $144 \mathrm{p}$.

Clarke, K.R. \& Warwick, R.M. 2001. Change in marine communities: an approach to statistical analysis and interpretation. $2^{\text {nd }}$ ed., Plymouth, PRIMER-E, UK, 172p.

Culver, S.J. 1988. New Foraminiferal Depth Zonation of the Northwestern Gulf of Mexico. SEPM, Palaios, 3: 39-85.

Dajoz, R. 1983. Ecologia Geral. Petrópolis, Vozes, 4⿳a ed., 472p. Dias, G.T.M. 2000. Granulados bioclásticos - algas calcárias. Revista Brasileira de Geofísica, 18(3): 307-318.

Drooger, C.W. \& Kaasschietter, J.P. H. 1958. Foraminifera of Orenoco-Trinidad-Paria shelf expedition. Verhandelingen der Koninklijke Nederlandse Akademie van Wetenschappen. Afd. Natuurkunde, v. 4, 108p.

Eichler, P.P.B., Eichler, B.B., Gupta, B.K.S. \& Rodrigues, A.R. 2012. Foraminifera as indicator of marine pollutant contamination on inner continental shelf of southern Brazil. Marine Pollution Bulletin, 64: 22-30.

França, A.M.C. 1979. Geomorfologia da Margem Continental Leste Brasileira e da Bacia Oceânica Adjacente. In: Chaves, H.A.E. (ed), Geomorfologia da Margem Continental Brasileira e das Áreas Oceânicas Adjacentes. Série Projeto REMAC, v. 7, p. 89-127.

Ferreira, D.F. 2008. Estatística multivariada. Lavras, Editora UFLA, 662p.

Figueiredo, S.M.C., Machado, A.J., Araújo, T.M.F. \& Araújo, H.A.B. 2011. Zoneamento batimétrico das assembleias de foraminíferos da plataforma e talude continentais do município de Conde, Bahia. Gravel, 9 (1): 1-10.

Hair, J.F., Anderson, R.E., Tatham, R.L. \& Black, W.C. 2005. Análise multivariada de dados. Porto Alegre: Bookman, 593p.

Hallock, P. 1984. Distribution of selected species of living algal symbiont-bearing foraminifera on two Pacific coral reefs. Journal Foraminiferal Research, 23 (3): 162-179.

Hohenegger, J., Yordanova, E., Nakano, Y. \& Tatzreiter, F. 1999. Habitats of larger foraminifera on the upper reef slope of Sasoko Island, Okinawa, Japan. Marine Micropaleontology, 36: 109-168.

Landim, P.M.B. 2011. Análise estatística de dados geológicos multivariados, São Paulo. Oficina de Textos, 239p.

Lattin, J., Carroll, J.D. \& Green, P.E. 2011. Análise de dados multivariados, São Paulo, Cengage Learning, 455p.

Leipnitz, I.I. \& Leipnitz, B. 1996. Nova proposta de subdivisão biogeográfica com base nos foraminíferos para as porções norte e nordeste da Plataforma Continental Brasileirra. In: CONGRESSO BRASILEIRO DE GEOLOGIA, 39, Salvador - Bahia, 1996. Resumos Expandidos, p. 270-273.

Li, C., Jones, B. \& Kalbfleisch, W.B.C. 1998. Carbonate sediment transport path ways based on foraminífera: case study from Frank Sound, Grand Cayman, Britsh West Indies. Sedimentology 45: 109-120.

Loeblich, A.R. \& Tappan, H. 1988. Foraminiferal genera and 
their classification. Van Nostrand Reinhold Ed., New York, USA, 970p, $847 \mathrm{pl}$.

Macedo, D.L.S. \& Machado, A.J. 1995. A fauna de foraminíferos dos sedimentos superficiais de uma área selecionada na plataforma continental do estado da Bahia (Arembepe ao Morro de São Paulo). Acta Geologica Leopoldensia, 42: 119-137.

Machado, A.J., Andrade, E. D. \& Araújo, H.A.B. 2006. Fauna de Foraminíferos do Litoral Norte do Estado da Bahia. Revista de Geologia, 19(2): 147-154.

Mackensen, A. \& Hald, M.1988. Cassidulina teretis Tappan and C. laevigata d'Orbigny: their modern and late Quaternary distribution in northern seas. Journal of Foraminiferal Research, 18: 16-24.

Miao, Q. \& Thunell, R.C. 1993. Recent deep-sea benthic foraminiferal distributions in the south China and Sulu Seas. Marine Micropaleontology, 22: 1-32.

Mingoti, S. A. 2005. Análise de dados através de métodos de estatísticas multivariadas: uma abordagem aplicada. Belo Horizonte, Editora UFMG, 297p.

Murray, J.W. 1991. Ecology and Palaeocology of benthic foraminífera. Longman Scientific \& Techinical, 397p.

Murray, J.W. 2006. Ecology and Applications of Benthic Foraminifera. Editora Cambridge University Press. 426p.

Nees, S. 1998. Ground truth in palaeoceanography - good news from the sea floor. In: INTERNATIONAL CONFERENCE ON PALAEOCEANOGRAPHY, 6, Lisboa. Proceedings..., 5p.

Passos, R.F., Souza, S.H.M. \& Mahiques. M. M. 2001. Mudanças ambientais ocorridas entre Abrolhos (BA) e Cabo Frio (RJ) ao longo do Holoceno, e sua resposta nas associações de foraminíferos. Pesquisas em Geociências, 28 (2): 223231.

Pawlowski, J. \& Holzmann, M. 2008. Diversity and geographic distribution of benthic foraminifera: a molecular perspective. Biodiversity and Conservation, 17: 317-328.

Manuscrito 498

Editores: Marina Bento Soares e Paulo A. Souza.
PNUMA - Programa das Nações Unidas para o Meio Ambiente. 2004. Perspectivas do Meio Ambiente Mundial 2002 GEO-3. Nairobi, Kenya, Disponível em: <www.unep.org/ GE0/geo3/index.htm>. Acessado em: 16 abr. 2012.

R Development Core Team. 2012. R: a language and environment for statistical computing. Vienna, Austria. Disponível em: < http://www. R-project.org >. Acessado em: junho de 2012.

Rencher, A.C. 2002. Methods of multivariate analysis. New York: J. Wiley, 708p.

Renema, W. 2006. Large benthic foraminífera from the deep photic zone of a mixed siliciclastic-carbonate shelf off East Kalimantan, Indonesia. Marine Micropaleontology, 68:73-82.

Schlee, J. 1973. Atlantic Continental Shelf and Slope of the United States sediment texture of the northeastern part. U.S. Geological Survey Professional Paper, 529-L, 64p.

Seiglie, G.A. 1968. Relationship between the distribution of Amphistegina and the sumerged Pleistocene reefs off western Puerto Rico. Tulane Studies in Geology, 6: 138147.

Shepard, F.S. 1954. Nomenclature based on sand-silt-clay ratios. Journal of Sedimentary Petrology, 24(3): 151-158.

Testa, V. 1996. Quaternary sediments of the shallow shelf, Rio Grande do Norte, WE Brazil. London, 416p. PhD thesis, Program Postgraduate studies in Geology, Royal Holloway, University of London.

Vieira, F.S. 2011. Caracterização microbiofaciológica e ambiental com base em foraminíferos bentônicos na plataforma continental da bacia de Campos, Rio de Janeiro. 137p. Tese de Doutorado, Programa de Pós-graduação em Geologia, Instituto de Geociências, Universidade Federal da Bahia.

Wentworth, C.K. 1962. A scale of grade and class terms for clastic sediments. Journal Geology, 30: 377-392. 
